This document is the Accepted Manuscript version of a Published Work that appeared in final form in Chemical Communications, copyright (C) Royal Society of Chemistry after peer review and technical editing by the publisher. To access the final edited and published work see http://pubs.rsc.org/en/content/articlelanding/2016/cc/c6cc04474c\#!divAbstract

\title{
Supramolecularly Fine-Regulated Enantioselective Catalysts
}

\author{
Mónica Vaquero, ${ }^{a}$ Laura Rovira, ${ }^{a}$ and Anton Vidal-Ferran*a,b \\ anstitute of Chemical Research of Catalonia (ICIQ) \& The Barcelona Institute of Science and Technology, Avgda. Països Catalans 16, 43007 Tarragona, Spain. \\ ${ }^{b}$ ICREA, Pg. Lluís Companys 23, 08010 Barcelona. \\ E-mail:avidal@iciq.cat
}

The use of supramolecular interactions in catalysis has undergone major growth in the last decade and has contributed to the major advances achieved in the field of enantioselective catalysis. Of the various approaches that use supramolecular interactions in enantioselective catalysis, this article highlights different supramolecular strategies to generate a set of enantiopure ligands (or enantioselective catalysts) that retain the majority of the backbone's structural features, yet at the same time incorporate subtle changes at its active site that depend on the structural characteristics of the regulation agent (RA) employed.

\section{Introduction}

Enantioselective catalysis enables selective pathways for converting simple compounds into enantiomerically pure complex molecules. It has evolved greatly since the early 1970 s to now encompass nearly any transformation subject to threedimensional bias. ${ }^{1}$ The critical step in most enantioselective processes is the assembly of a supramolecular system around the catalytic site. This involves the substrate, the metal precursor, if present, and an enantiopure molecule (the chiral ligand). In metal-mediated transformations, the metal centre provides a low-energy reaction pathway that enables catalysis, whereas the enantiomerically pure ligand enables the formation of enantiopure (or enantioenriched) products. In metal-mediated asymmetric transformations, the metal centre and ligand have the complementary functions indicated above, whereas in organocatalysis, the enantiopure organic molecule alone plays both roles by providing a low energy reaction pathway and enabling the formation of enantiopure (or enantioenriched) products. $^{2}$ The first chiral ligands to be employed in enantioselective catalysis were mostly derived from the "chiral pool". ${ }^{3}$ Practitioners of enantioselective catalysis soon realised that, because of the limited structural diversity among ligands derived from natural products, they were unlikely to provide a satisfactory response to all conceivable selectivity demands in catalysis (reactions, substrates, reagents, etc.). Thus, researchers realised that they needed to harness asymmetric synthesis to broaden the repertoire of ligand scaffolds, to incorporate all types of stereogenic elements in the ligand, and to functionalize ligands with diverse functional groups that bind the desired metal centre (in transition metal-based transformations) or interact with the substrates/reagents (in organocatalysed processes). ${ }^{4}$ The use of supramolecular interactions in catalysis has undergone major growth in the last decade and has also contributed to the major advances achieved in the field of enantioselective catalysis. In addition to the situations in which supramolecular interactions participate exclusively in a catalytic event, ${ }^{5}$ supramolecular chemistry in enantioselective catalysis has a range of other uses:
First and foremost, supramolecular interactions have been widely used to construct the backbone of enantiopure ligands by attaching suitably designed building blocks through noncovalent and metal-ligand interactions. The building blocks contain the binding groups required for the desired catalysis as well as the motifs necessary for supramolecular assembly. This synthetic methodology has enabled libraries of structurally diverse enantiopure ligands or catalysts to be synthesised with greater ease than for standard covalent chemistry. The use of supramolecular interactions to construct ligands for enantioselective catalysis, or catalysts themselves, has been widely reviewed ${ }^{6}$ and is outside the scope of this text.

Second, supramolecular interactions in enantioselective catalysis have also been exploited by placing in the ligand or catalyst well-designed functional groups capable of supramolecularly interacting with the substrate. Substrate-, chemo-, diastereo- and/or enantio-selectivities have been improved using this strategy, which relies on the precise positioning of the substrate relative to the catalytic site. Reported examples encompass both transition-metal- and metal-free catalysed enantioselective transformations and will not be discussed in this text, as these have been recently reviewed. $^{7}$

Encapsulation of the catalytic species in a molecular container constitutes the third supramolecular strategy that has been applied in catalysis. Amongst other advantages, encapsulating the catalytic system has led to rate enhancement by increasing the effective concentration of the reagents within a confined space, to unusual selectivity within the molecular container and to the stabilisation of otherwise unstable molecules within the cavity. Many of these applications refer to achiral transformations and there is very little literature providing examples of enantioselective transformations within a confined space. This topic has been the object of recent reviews and is also outside the scope of this text. ${ }^{8}$

The fourth and last supramolecular strategy that has been implemented in enantioselective catalysis has sought to override one of the intrinsic limitations of enantioselective catalysts: their lack of generality. It is well known to 
practitioners in the field that structural changes in the substrate(s) and/or reagent(s) often translate to a loss of enantioselectivity. A common strategy to improve the generality of a catalyst is based on a modular ligand design and ligand tuning. ${ }^{9}$ Libraries of structurally related ligands have also been prepared (in many cases through parallel synthesis ${ }^{10}$ ) and assessed by automated high-throughput screening to rapidly identify high-performing catalysts for a specific transformation and substrate. ${ }^{10,11}$ With the aim of reducing the synthetic efforts associated with the above mentioned strategies, practitioners have also harnessed supramolecular chemistry to produce libraries of enantioselective catalysts, whose members preserve the main structural characteristics of the whole set but also incorporate subtle geometrical differences at the catalytic site. Hence, the members of these libraries of related catalysts are capable of geometric adaptation to the requirements of a given substrate for high enantioselectivity.

Two strategies have been developed to achieve these goals:

- Supramolecular regulation onto an already formed enantioselective catalyst: this approach resembles allosteric modulation or "allosterism", which is one of Nature's most exquisite mechanisms of action in enzyme catalysis. ${ }^{12}$ Allosteric modulation of a biocatalyst refers to the modification of the biocatalyst's active site when an effector molecule binds at a distinct site on the same biocatalyst (known as the allosteric site or regulation site). Supramolecularly fine-regulated enantioselective catalysts belonging to this category possess a catalytic site with a welldefined three-dimensional structure suitable for enantioselective catalysis and a distal regulation site containing a supramolecular motif capable of interacting with a regulation agent (RA). In this way, the library of enantioselective catalysts that results from the binding of an array of geometrically diverse RAs to the regulation site not only preserves most of the structural characteristics but also incorporates structural peculiarities that depend on the size and shape of the RA employed.

- Supramolecular regulation onto a pro-chiral ligand: the principle of this approach is similar to that summarised above with one crucial exception. The three-dimensional structure of the catalytic site is not well defined in the absence of a regulation agent. The addition of an enantiopure regulation agent creates chirality and the size and shape of the RA employed also determine the geometry of the catalytic site.

It should be recalled at this point that this feature article focuses only on the progress on systems that fall within the two aforementioned categories (supramolecular regulation of enantioselective catalysts involving major alterations of the principal structural features of the catalyst has been the object of recent reviews ${ }^{13}$ and is outside the scope of this text). Furthermore, it should be noted that this perspective article highlights published pieces of work only when the authors demonstrate the regulation ability of a set of RAs on an array of substrates. Examples describing the use of only one RA for a whole array of substrates have not been included in the present article because the authors regard these examples as referring to the construction of the catalyst ${ }^{6,13}$ and not to the regulation effects induced by the external molecule. Analogously, the present article also excludes examples describing an array of external molecules or RAs for only one substrate.

\section{Discussion}

The discussion is divided into two sections corresponding to the two aforementioned different strategies.

\subsection{Supramolecular regulation on an already formed enantioselective catalyst}

In this strategy, regulation occurs when a catalytic site is modified by the interaction of an external unit (regulation agent; RA) with a distinct specific regulation site. The following discussion is divided into different sections corresponding to the different supramolecular motifs that have been employed as regulation sites.

2.1.1. Catalytic systems regulated by interactions of a regulation agent with an (aza-)crown-ether motif. Cyclic crownethers and their nitrogenated analogues form very stable complexes with charged species (i.e. metal ions, halide anions, carboxylates, etc.). ${ }^{14}$ Furthermore, crown-ethers have become popular supramolecular motifs due to the ease with which their size, shape and topology can be varied and the fact that synthetic strategies for preparing them are well-established. ${ }^{14}$ Ito and coworkers $^{15}$ pioneered the field of supramolecularly fine-regulated enantioselective catalysts for asymmetric allylic substitutions (AASs) by incorporating an aza-crown-ether motif as a regulation site in their bisphosphine ligand design (Fig. 1). The underlying principle in the design of the catalyst consisted of introducing a secondary interaction ${ }^{16}$ between the reacting nucleophile (enolates generated from S1 or S2 by using alkali metal salts as bases) and the azacrown-ether motif. It was envisaged that the metal enolate would form an inclusion complex with the aza-crown-ether. In doing so, it was expected that the reacting nucleophile would be placed in close proximity to the allyl group bound to the palladium centre with an overall improvement in the reaction rate and in the stereocontrol of the reaction by reducing the degrees of freedom in the intervening transition states (TSs). Reactions of the enolates derived from S1 or S2 with allyl acetate were carried out in the presence of in situ formed palladium catalysts (equimolar amounts of $\mathrm{Pd}_{2}(\mathrm{dba})_{3} \cdot \mathrm{CHCl}_{3}$ and the corresponding ligand) and an array of alkali metal fluorides (i.e. $\mathrm{KF}, \mathrm{RbF}$ or $\mathrm{CsF}$ ) as bases. The authors used an array of bases because they believed that the size of the cation could

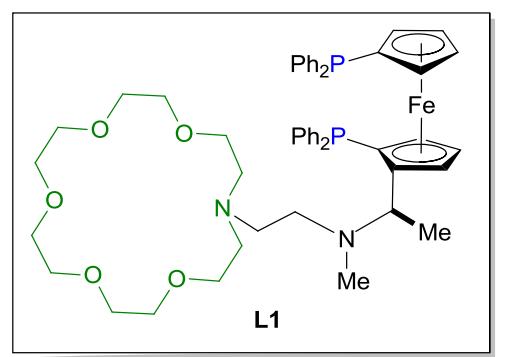

Fig. 1. Supramolecularly regulated ligand for AASs reported by lto et al. 
Table 1. Catalytic results obtained for AASs reported by Ito et al.

$$
\begin{aligned}
& \mathrm{CH}_{2}=\mathrm{CHCH}_{2} \mathrm{OAC}(1.5 \text { equiv. }) \\
& \mathbf{R A}(2 \text { equiv. }), \mathrm{DCM},-25^{\circ} \mathrm{C}
\end{aligned}
$$

$\mathbf{S} 1 \mathrm{G}=-\mathrm{CH}_{2}-\mathrm{R}=\left(-\mathrm{CH}_{2}-\right)_{3}$

S2 $\mathrm{G}=\mathrm{O}-\mathrm{tBu}, \mathrm{R}=\mathrm{Me}$

\begin{tabular}{lllcll}
\hline Entry & $\begin{array}{l}\text { Carbanion } \\
\text { derived } \\
\text { from }\end{array}$ & RA & $\begin{array}{l}\text { Yield } \\
(\%)\end{array}$ & $\begin{array}{l}\text { ee } \\
(\%, \text { config.) }\end{array}$ & $\begin{array}{l}\text { Regulation } \\
\text { effects in } \\
\text { ee }^{a}(\%)\end{array}$ \\
\hline 1 & S1 & KF & 33 & $25(R)$ & - \\
2 & S1 & RbF & 57 & $38(R)$ & +13 \\
3 & S1 & CsF & 31 & $31(R)$ & +6 \\
4 & S2 & KF & 95 & $51(R)$ & +17 \\
5 & S2 & RbF & 95 & $60(R)$ & +26 \\
6 & S2 & CsF & 91 & $34(R)$ & -
\end{tabular}

${ }^{a}$ Calculated with respect to the lowest ee described.

influence the relative arrangement of the attacking nucleophile and the allyl group. The ability to modify the arrangement of reactants through supramolecular interactions constitutes the regulation mechanism in this catalytic system. After an optimisation process, ligand $\mathbf{L} 1$ was found to be the optimal one for achieving high ees in the AASs of allyl acetate with the nucleophiles derived from S1 and S2. The authors also found that the combined use of RbF with ligand L1 provided the highest conversions and ees in both cases. The authors reported that the affinity between $\mathrm{RbF}$ and the aza-crownether motif in ligand L1 was higher than those for KF and CsF. The better complementarity between RbF and the aza-crownether motif translated into more efficient regulation effects in terms of enantioselectivity for RbF than those observed for KF (compare entries 2 with 1 for $\mathbf{S 1}$ and 5 with 4 for S2, in Table 1) or CsF (compare entries 2, 3, 5 and 6 in Table 1).

Vidal-Ferran et al. reported the preparation of bisphosphine ligand L2, which incorporates a crown-ether motif as a regulation site, and its use in rhodium-mediated asymmetric hydrogenations (AHs). ${ }^{17}$ The authors envisaged that binding a regulation agent to the crown-ether motif could modulate the catalyst performance by modifying the dihedral angle $\theta$ of the biaryl unit (see Fig. 2a for a general representation of the regulation principle). The importance of the geometrical parameter $\theta$ in the performance of a transition metal-based catalyst is well documented in the literature, as it is associated with the natural bite-angle $\beta$ of a ligand to the metal centre (see Fig. 2a). ${ }^{18}$ Rhodium complexes derived from bisphosphine $\mathbf{L} \mathbf{2}$ were efficient catalysts in the $\mathrm{AH}$ of S3 in terms of activity, though the ees remained moderate (ees ranging from $56 \%$ to $62 \%$ in favour of $(S)$-P3 and from $26 \%$ to $30 \%$ for (S)-P4, see Table 2). In terms of the $\mathrm{AH}$ of $\mathbf{S} \mathbf{3}$ in the presence of a set of RAs, small but noticeable regulation effects on the ee were observed. The maximal increment in the ee was observed using the enantiomerically pure ammonium salt RA1 as the RA. In contrast, the best enantioselectivity for $\mathbf{S 4}$ was obtained in the absence of an RA.
These results indicate that even for the same combination of ligand and RA, the sign and magnitude of the regulation effects depend on the substrate. Though the regulation effects were small in magnitude, the authors demonstrated that a library of bisphosphines could be easily generated with this strategy by varying the regulation agent.

a)

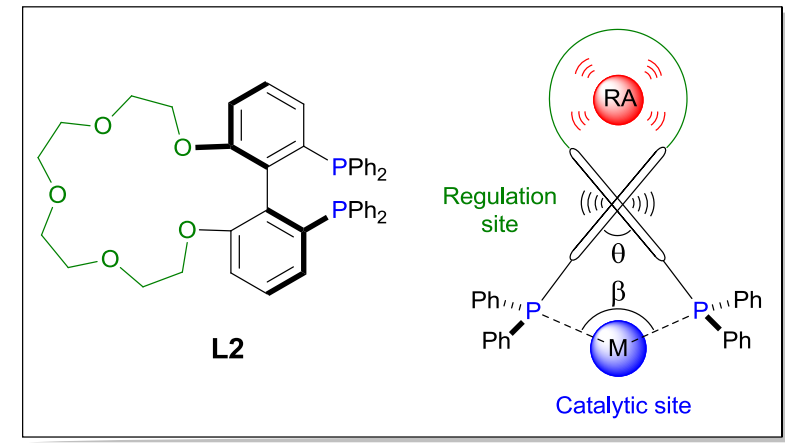

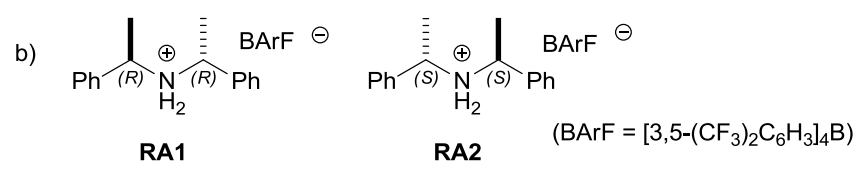

Fig. 2. (a) Ligand structure and regulation principle for AHs reported by Vidal-Ferran et al.; (b) Ammonium salts employed as regulation agents.

Table 2. Catalytic results obtained for AHs reported by Vidal-Ferran et al.

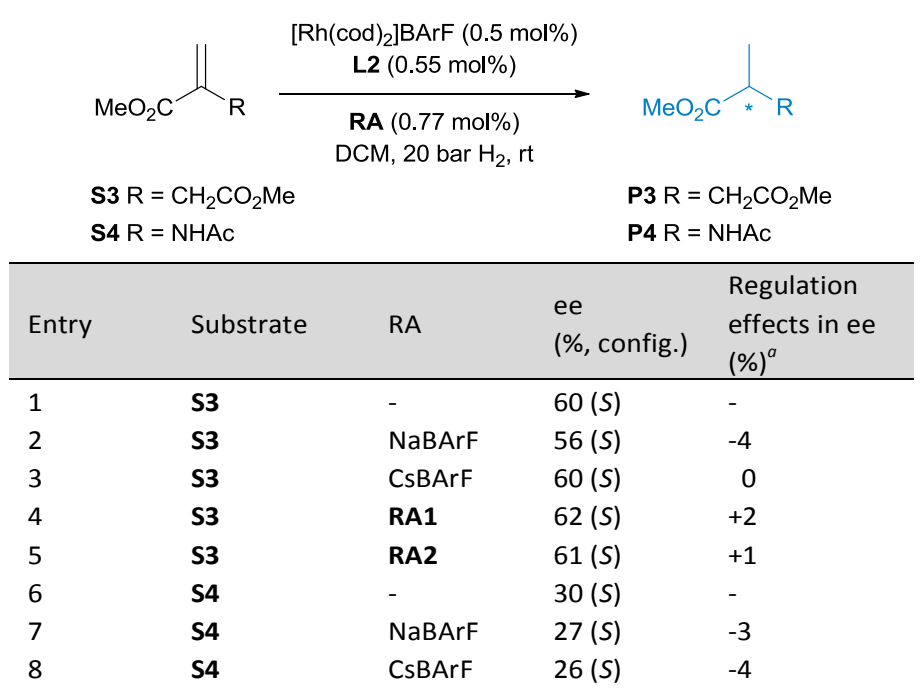

${ }^{a}$ Calculated for each substrate with respect to the experiment in the absence of an RA.

Recently, Wu and $\mathrm{Li}$ et al. ${ }^{19}$ have designed a new supramolecularly regulated biphosphine ligand containing pyridyl-aza-crown-ether motifs to be applied in the AH of $\alpha$ dehydroamino acid and quinoline derivatives. The new ligand L3 incorporated two pyridyl-aza-crown-ether units (see Fig. 3 for the structure), which bind an array of BArF salts in a 1:2 relative stoichiometry between $\mathbf{L} 3$ and the BArF salt. ${ }^{19}$ The use of an array of alkali metal BArF salts in the asymmetric hydrogenation of $\alpha$-dehydroamino acid derivatives S5-S7 mediated by rhodium complexes derived from $\mathbf{L} 3$ translated into complete conversion and different enantioselectivities depending on the RA used (NaBArF provided the highest ee, 
entry 5 in Table 3). Of the various weakly coordinating anions (WCA) constituting the RAs, the BArF anion provided the highest regulation effects during the hydrogenation of $\mathbf{S 5}$ with $\mathrm{G}=\mathrm{H}$ (compare entries 5-7 in Table 3). The authors suggest that the weaker coordinating ability of the BArF anion favours strong binding of NaBArF to the crown ether motif. Binding studies between a bulky ammonium BArF salt (i.e. $\left.(n \mathrm{Bu})_{4} \mathrm{NBArF}\right)$ and the crown ether motifs revealed a weak interaction and the effects of $(n \mathrm{Bu})_{4} \mathrm{NBArF}$ on the performance of the catalyst were also minimal (compare entries 1 and 8 in Table 3). Furthermore, enhancements in the enantioselectivity of up to $11 \%$ ee in the hydrogenation of S5 with $\mathrm{G}=\mathrm{H}$ were achieved when NaBArF was employed as the RA (compare entries 1, 2 and 5 in Table 3; the reader is referred to the original work for the whole set of results). The authors expanded the scope of the reaction to a set of structurally diverse $\alpha$-dehydroamino acid derivatives (see the scheme in Table 3 and the original reference for the whole set of substrates studied). ${ }^{19}$ The highest regulation effects were observed for S5 with G = 2-F, for which NaBArF increased the conversion by $62 \%$ and the enantioselectivity by $22 \%$ with respect to the hydrogenation in the absence of an RA (compare entries 11 and 12 in Table 3).

This supramolecular regulation approach was also applied to the iridium-mediated asymmetric hydrogenation of quinolines. The resulting hydrogenated products were obtained with excellent enantioselectivities $(90-97 \%$ ee, Table 4$)$, but the regulation effects were smaller than those obtained in rhodium-mediated AHs of functionalised alkenes, with enhancements of up to $10 \%$ (see entries 1 and 2 in Table 4).

In short, it is interesting to note that supramolecularly regulated ligand L3 performs better in terms of enantioselectivity in $\mathrm{Rh}$ - and Ir-mediated $\mathrm{AHs},{ }^{20}$ than the ligand lacking the two crown ether motifs (i.e. Xyl-P-Phos ${ }^{21}$ ).

2.1.2. Catalytic systems containing a polyether linear chain as the regulation site. Metallacrown-ethers are formed by combining a metal precursor with a linear polyether chain containing functional groups at the $\alpha$ and $\omega$ positions capable of coordinating to the metal centre. Fan et $a .^{22}$ identified metallacrown-ethers ${ }^{23}$ as ideal scaffolds for developing supramolecularly regulated enantioselective catalysts: metallacrown derivatives simultaneously contain a plausible catalytic group (the metal centre) and a supramolecular motif capable of acting as a

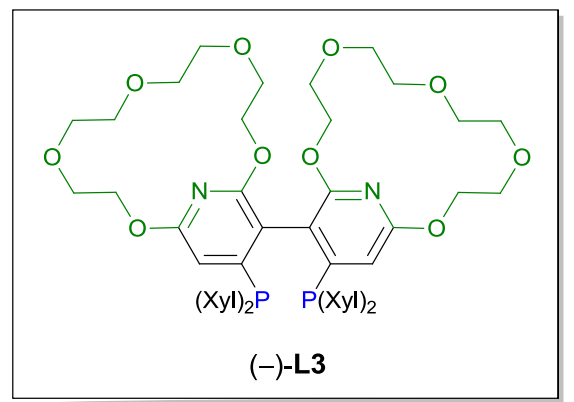

Fig. 3. Supramolecularly regulated ligand for $\mathrm{AHs}$ reported by Wu and Li et al.
Table 3. Catalytic results obtained for Rh-mediated AHs reported by Wu and Li et al.

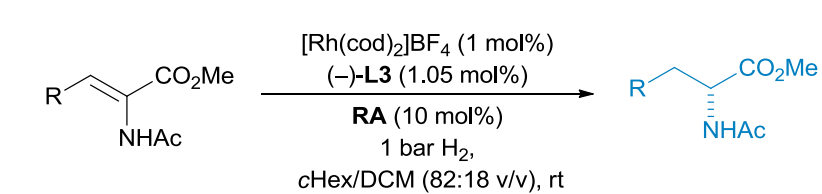

S5 $\mathrm{R}=\mathrm{G}-\mathrm{C}_{6} \mathrm{H}_{4^{-}}$

S6 $R=$ Furan-2-yl

P5 $\mathrm{R}=\mathrm{G}-\mathrm{C}_{6} \mathrm{H}_{4}-$

S7 $R=$ Thiophen-3-yl

\begin{tabular}{|c|c|c|c|c|c|}
\hline Entry & Substrate & $\begin{array}{c}\text { RA } \\
\text { (mol\%) }\end{array}$ & $\begin{array}{c}\text { Conv. } \\
(\%)\end{array}$ & $\begin{array}{c}\text { ee (\%, } \\
\text { config.) }\end{array}$ & $\begin{array}{c}\text { Regulation } \\
\text { effects in } \\
\text { ee }(\%)^{a}\end{array}$ \\
\hline $1^{b}$ & S5, G = H & - & $>99$ & $82(R)$ & - \\
\hline $2^{b}$ & S5, $G=H$ & NaBArF (2) & $>99$ & $88(R)$ & +6 \\
\hline $3^{b}$ & S5, G = H & LiBArF (2) & $>99$ & $84(R)$ & +2 \\
\hline $4^{b}$ & S5, $G=H$ & KBArF (2) & $>99$ & $86(R)$ & +4 \\
\hline $5^{b}$ & S5, $G=H$ & NaBArF (10) & $>99$ & $93(R)$ & +11 \\
\hline $6^{b}$ & S5, G = H & $\mathrm{NaBF}_{4}(10)$ & 68 & $81(R)$ & -1 \\
\hline $7^{b}$ & S5, G = H & $\mathrm{NaPF}_{6}(10)$ & 96 & $83(R)$ & +1 \\
\hline $8^{b}$ & S5, G = H & $(n \mathrm{Bu})_{4} \mathrm{NBArF}(10)$ & 91 & $84(R)$ & +2 \\
\hline 9 & S5, G = 2-OMe & - & 69 & $78(R)$ & - \\
\hline 10 & S5, G = 2-OMe & NaBArF (10) & 93 & $99(R)$ & +21 \\
\hline 11 & S5, G = 2-F & - & 33 & $76(R)$ & - \\
\hline 12 & S5, $G=2-F$ & NaBArF (10) & 95 & $98(R)$ & +22 \\
\hline 13 & S5, G = 3-OMe & - & 42 & $77(R)$ & - \\
\hline 14 & S5, G = 3-OMe & $\mathrm{NaBArF}(10)$ & 93 & $98(R)$ & +21 \\
\hline 15 & S5, G = 4-F & - & 71 & $84(R)$ & - \\
\hline 16 & S5, $G=4-F$ & NaBArF (10) & 92 & $98(R)$ & +14 \\
\hline 17 & S6 & NaBArF (10) & 90 & $97(R)$ & - \\
\hline 18 & S7 & NaBArF (10) & 88 & $97(R)$ & - \\
\hline
\end{tabular}

${ }^{a}$ Calculated for each substrate with respect to the experiment in absence of an RA. ${ }^{b}$ Reaction performed in DCM.

regulation site (polyether motif) by binding a complementary external unit (RA). It should be noted at this point that, like cyclic crown-ethers, linear polyether groups are also capable of binding charged species such as metal ions, carboxylates, etc. ${ }^{24}$ Fan et al. pioneered the use of supramolecularly regulated polyether-based ligands for rhodium-mediated asymmetric hydrogenations $(\mathrm{AHs}){ }^{22}$ These authors reported the first example of rhodium complexes derived from bisphosphitepolyether ligands, whose catalytic performance in terms of enantioselectivity in $\mathrm{AH}$ was enhanced by the addition of an RA. Fan et al. first investigated the effect of the linker length on the catalytic performance of the metallacrown-ether catalyst. Ligands with five, six or seven ethyleneoxy units in the polyether chain provided moderate enantioselectivities in the absence of an RA, which were associated by the authors with their high flexibility (although the results for ligand L4 (Fig. 4), which contains six ethyleneoxy units, are indicated in Table 5, the reader is referred to the original work ${ }^{22}$ for the results for the other two ligands). The efficiency of $\mathbf{L} \mathbf{4}$ could be enhanced by adding an RA (i.e. LiBArF, NaBArF or KBArF) capable of interacting with the polyether chain. 
Table 4. Catalytic results obtained for Ir-mediated AHs by Wu and Li et al.

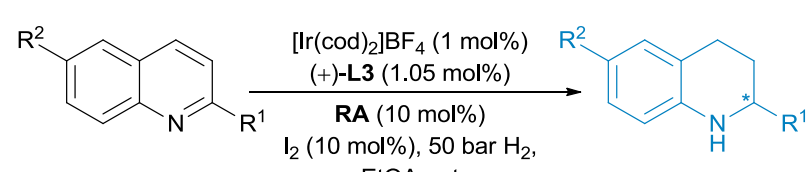
EtOAc, rt

P8 $\mathrm{R}^{1}=n \mathrm{Pr}, n \mathrm{Bu}, n$ pentyl, Me $\mathrm{R}^{2}=\mathrm{H}, \mathrm{F}$

\begin{tabular}{|c|c|c|c|c|}
\hline Entry & Substrate & RA & $\begin{array}{c}\text { ee (\%, } \\
\text { config.) }\end{array}$ & $\begin{array}{l}\text { Regulation } \\
\text { effects in } \\
\text { ee }(\%)^{a}\end{array}$ \\
\hline 1 & S8, $R^{1}=M e, R^{2}=H$ & - & $87(R)$ & - \\
\hline 2 & S8, $R^{1}=M e, R^{2}=H$ & $\mathrm{NaBArF}$ & $97(R)$ & +10 \\
\hline 3 & S8, $\mathrm{R}^{1}=n \mathrm{Pr}, \mathrm{R}^{2}=\mathrm{H}$ & $\mathrm{NaBArF}$ & $97(R)$ & - \\
\hline 4 & S8, $\mathrm{R}^{1}=n \mathrm{Bu}, \mathrm{R}^{2}=\mathrm{H}$ & $\mathrm{NaBArF}$ & $96(R)$ & - \\
\hline 5 & S8, $\mathrm{R}^{1}=n$ pentyl, $\mathrm{R}^{2}=\mathrm{H}$ & $\mathrm{NaBArF}$ & $96(R)$ & - \\
\hline 6 & S8, $R^{1}=M e, R^{2}=F$ & $\mathrm{NaBArF}$ & $90(R)$ & - \\
\hline \multicolumn{5}{|c|}{$\begin{array}{l}{ }^{a} \text { Calculated for each substrate with respect to the experiment in absence of an } \\
\text { RA. }\end{array}$} \\
\hline
\end{tabular}

NaBArF provided the highest increase in the enantioselectivity of the $\mathrm{AH}$ of $\mathbf{S 5}$ with $\mathrm{G}=\mathrm{H}$ (see entry 3 in Table 5; increase in ee up to $11 \%$ ). The authors suggested that the difference in the abilities of ligand $\mathbf{L} \mathbf{4}$ to bind LiBArF, NaBArF or KBArF translated into different regulation effects. A binding competition experiment between 18-crown-6 ether, KBArF and $\mathbf{L} \mathbf{4}$ helped to determine the role of the alkali-metal salts in the regulation event. The higher affinity of 18-crown-6 for KBArF with respect to $\mathbf{L} \mathbf{4}$ led to an enantioselectivity similar to that obtained in the absence of an RA. Once the optimal catalytic system had been identified, a series of $\alpha$ dehydroamino acids were hydrogenated by employing Rhcomplexes derived from $\mathbf{L} 4$ as catalyst and NaBArF as RA. As shown in Table 5, AHs proceeded efficiently with full conversions, excellent enantioselectivities (ees ranged from $94 \%$ to $98 \%$ ee; see entries $5-8$ in Table 5) and positive regulation effects (increases in the ee ranging from $5 \%$ to $17 \%$ ) when NaBArF was used as the RA.

More recently, Fan and $\mathrm{He}$ et al. have reported the preparation of supramolecularly regulated phosphinephosphite ligand $\mathbf{L 5}$ and its performance in rhodium-mediated AHs (Fig. 5). ${ }^{25}$ The design principle was the same as for $\mathbf{L 4}$, though metallacrown-ethers with different coordinating groups at their $\alpha$ and $\omega$ positions were unknown before the study by Fan and He et al. The catalytic system that provided higher enantioselectivities in the AH of $\alpha$-arylenamide $\mathbf{S 9}$ ( $G$ = $\mathrm{H})$ was derived from ligand $\mathbf{L 5}$. The use of KBArF as the RA provided the highest enhancements in enantioselectivity for all RAs assayed (ee enhancement up to $9 \%$ ee; see entry 4 in Table 6 for all RAs studied).

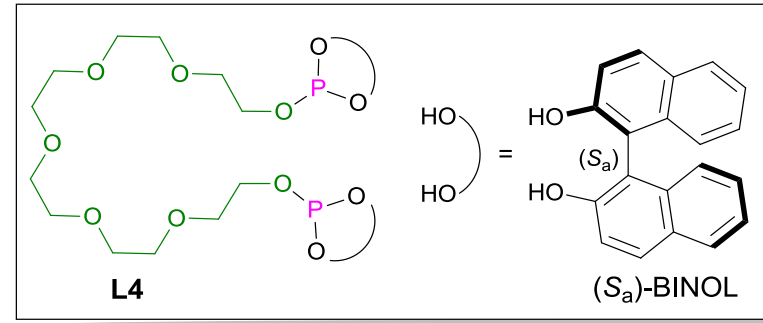

Fig. 4. Supramolecularly regulated ligand for AHs reported by Fan et al.

Table 5. Catalytic results obtained for AHs by Fan et al.

$$
\begin{aligned}
& \text { Thh(cod })_{2} \mathrm{BF}_{\Delta}(1 \mathrm{~mol} \%)
\end{aligned}
$$

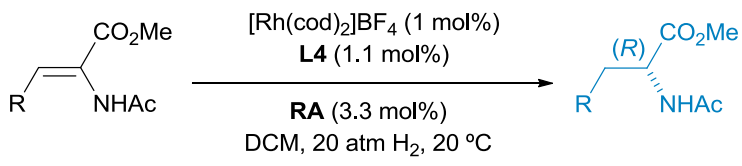

\begin{tabular}{|c|c|c|c|c|}
\hline Entry & Substrate & RA & $\begin{array}{c}\text { ee } \\
\text { (\%, config.) }\end{array}$ & $\begin{array}{c}\text { Regulation } \\
\text { effects in } \\
\text { ee }(\%)^{a}\end{array}$ \\
\hline 1 & S5, G = H & - & $84(R)$ & - \\
\hline 2 & S5, $G=H$ & LiBArF & $87(R)$ & +3 \\
\hline 3 & S5, G = H & $\mathrm{NaBArF}$ & $95(R)$ & +11 \\
\hline 4 & S5, $G=H$ & KBArF & $94(R)$ & +10 \\
\hline 5 & S5, G = 4-F & - & $83(R)$ & - \\
\hline 6 & S5, G = 4-F & $\mathrm{NaBArF}$ & $95(R)$ & +12 \\
\hline 7 & $\mathrm{~S} 5, \mathrm{G}=4-\mathrm{Cl}$ & - & $84(R)$ & - \\
\hline 8 & $\mathrm{~S} 5, \mathrm{G}=4-\mathrm{Cl}$ & $\mathrm{NaBArF}$ & $96(R)$ & +12 \\
\hline 9 & $\mathrm{~S} 5, \mathrm{G}=3-\mathrm{Cl}$ & - & $82(R)$ & - \\
\hline 10 & $\mathrm{~S} 5, \mathrm{G}=3-\mathrm{Cl}$ & $\mathrm{NaBArF}$ & $95(R)$ & +13 \\
\hline 11 & $\mathrm{~S} 5, \mathrm{G}=2-\mathrm{Cl}$ & - & $84(R)$ & - \\
\hline 12 & $\mathrm{~S} 5, \mathrm{G}=2-\mathrm{Cl}$ & $\mathrm{NaBArF}$ & $94(R)$ & +10 \\
\hline 13 & $\mathrm{~S} 5, \mathrm{G}=4-\mathrm{Me}$ & - & $86(R)$ & - \\
\hline 14 & S5, G = 4-Me & $\mathrm{NaBArF}$ & $94(R)$ & +8 \\
\hline 15 & $\mathrm{~S} 5, \mathrm{G}=4-\mathrm{NO}_{2}$ & - & $79(R)$ & - \\
\hline 16 & $\mathrm{~S} 5, \mathrm{G}=4-\mathrm{NO}_{2}$ & $\mathrm{NaBArF}$ & $96(R)$ & +17 \\
\hline 17 & S4 & - & $93(R)$ & - \\
\hline 18 & S4 & $\mathrm{NaBArF}$ & $98(R)$ & +5 \\
\hline
\end{tabular}

${ }^{a}$ Calculated for each substrate with respect to the experiment in absence of an RA.

Fan and He et al. also reported that the addition of KBArF had a rate accelerating effect on the $\mathrm{AH}$, which indicated that the addition of alkali metal salts also improved the activity of the metallacrown catalyst. $^{25}$ The authors attributed the differences in the regulation effects (or enhancements) on the ee of the hydrogenated product to the differences in the match of the RAs (i.e. LiBArF, NaBArF, KBArF or CsBArF) to the metallacrown motif. A series of $\alpha$-arylenamides (S9 and S10) were hydrogenated using the rhodium catalyst derived from $\mathbf{L}$ and KBArF as the RA. In general terms, the AHs of parasubstituted arylenamides proceeded with full conversions and high enantioselectivities (from 94 to $99 \%$ ee; see entries 6 to 15 in Table 6). Lower ees were obtained for the ortho- and meta-substituted analogues, although considerable regulation effects (enhancements of up to $+6 \%$ in the ee; see entry 17 in Table 6) were observed. 


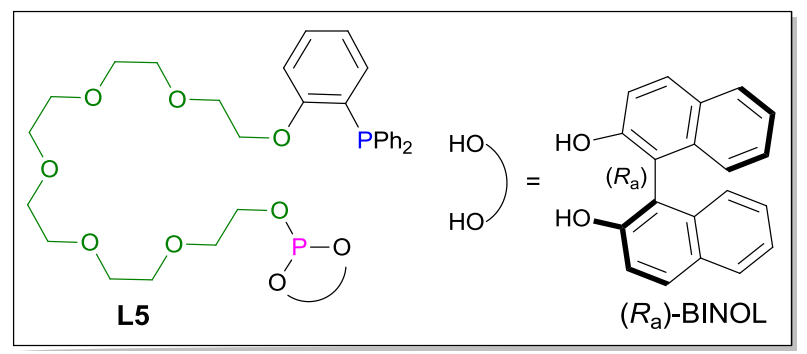

Fig. 5. Supramolecularly regulated ligand for AHs reported by Fan and He et al.

Table 6. Catalytic results obtained for AHs of $\alpha$-arylenamides by Fan and He et al.

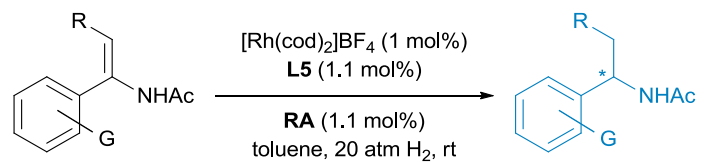

\begin{tabular}{|c|c|c|c|c|}
\hline \multicolumn{3}{|c|}{$\begin{array}{l}\text { s9 } R=H, G=H, M e, F, C F_{3}, C l, B r \\
\text { s10 } R=M e, G=H\end{array}$} & \multicolumn{2}{|c|}{$\begin{array}{l}\text { P9 } R=H, G=H, M e, F, C F_{3}, C l, B r \\
\text { P10 R }=M e, G=H\end{array}$} \\
\hline Entry & Substrate & RA & $\begin{array}{c}\text { ee } \\
\text { (\%, config.) }\end{array}$ & $\begin{array}{c}\text { Regulation } \\
\text { effects in } \\
\text { ee }(\%)^{a}\end{array}$ \\
\hline 1 & S9, G = H & - & $84(S)$ & - \\
\hline 2 & S9, G = H & LiBArF & $89(S)$ & +5 \\
\hline 3 & S9, G = H & $\mathrm{NaBArF}$ & $91(S)$ & +7 \\
\hline 4 & S9, G = H & $\mathrm{KBArF}$ & $93(S)$ & +9 \\
\hline 5 & S9, G = H & CsBArF & $92(S)$ & +8 \\
\hline 6 & $\mathrm{~S} 9, \mathrm{G}=4-\mathrm{Me}$ & - & $84(S)$ & - \\
\hline 7 & S9, G = 4-Me & KBArF & $96(S)$ & +12 \\
\hline 8 & S9, $G=4-F$ & - & $85(S)$ & - \\
\hline 9 & S9, $G=4-F$ & KBArF & $94(S)$ & +9 \\
\hline 10 & $\mathrm{Sg}, \mathrm{G}=4-\mathrm{CF}_{3}$ & - & $92(S)$ & - \\
\hline 11 & $\mathrm{~S} 9, \mathrm{G}=4-\mathrm{CF}_{3}$ & KBArF & $99(S)$ & +7 \\
\hline 12 & $\mathrm{~S} 9, \mathrm{G}=4-\mathrm{Cl}$ & - & $94(S)$ & - \\
\hline 13 & $\mathrm{S9}, \mathrm{G}=4-\mathrm{Cl}$ & KBArF & $99(S)$ & +5 \\
\hline 14 & S9, $\mathrm{G}=4-\mathrm{Br}$ & - & $93(S)$ & - \\
\hline 15 & S9, $\mathrm{G}=4-\mathrm{Br}$ & $\mathrm{KBArF}$ & $98(S)$ & +5 \\
\hline 16 & $\mathrm{S9}, \mathrm{G}=3-\mathrm{Cl}$ & - & $81(S)$ & - \\
\hline 17 & $\mathrm{S9}, \mathrm{G}=3-\mathrm{Cl}$ & KBArF & $87(S)$ & +6 \\
\hline 18 & $\mathrm{~S} 9, \mathrm{G}=2-\mathrm{Cl}$ & - & $66(S)$ & - \\
\hline 19 & S9, $\mathrm{G}=2-\mathrm{Cl}$ & KBArF & $70(S)$ & +4 \\
\hline 20 & S10 & - & $50(S)$ & - \\
\hline 21 & S10 & $\mathrm{KBArF}$ & $58(S)$ & +8 \\
\hline
\end{tabular}

${ }^{a}$ Calculated for each substrate with respect to the experiment in absence of an RA.

In between the publication dates of the studies on supramolecularly regulated metallacrown-based catalysts by Fan and He et al., ${ }^{22,25}$ Vidal-Ferran et al. reported the first generation of supramolecularly regulated $\alpha, \omega$-bisphosphites for asymmetric hydroformylations (AHFs). ${ }^{26}$ The design of the ligand was similar to that of $\mathbf{L} \mathbf{4}$ but incorporated a conformationally labile [1,1'-biphenyl]-2,2'-diol motif at the regulation site. The supramolecularly regulated $\alpha, \omega-$ bisphosphite was successfully applied to the AHF of terminal alkenes with highly positive regulation effects on the enantioselectivity (increases of up to $62 \%$ ee for vinyl acetate). ${ }^{26}$ Further optimization studies towards the optimal supramolecularly regulated ligand for this chemistry (i.e. optimal bisphosphite motif, optimal length of the polyether chain, necessity or not of having a conformationally labile [1,1'-biaryl]-2,2'-diol motif at the regulation site and the nature of the anionic component of the RA) led to an improved supramolecularly regulated catalytic system for the AHF of terminal alkenes (see ligand $\mathbf{L 6}$ in Fig. 6). ${ }^{27}$ These studies revealed that ligands with a conformationally labile [1,1'biaryl]-2,2'-diol motif at the regulation site led to lower conversions in the AHF of the chosen model substrate (i.e. vinyl acetate) and that phosphite groups derived from 3,3'bis(trimethylsilyl)-[1,1'-binaphthalene]-2,2'-diol provided the highest ees in $\mathrm{AHF}^{28}$ As regards the nature of the anionic component of the RA, the weakly coordinating BArF anion provided higher branched to linear $(b / I)$ ratios for vinyl acetate than those observed using other RAs containing the $\mathrm{BF}_{4}{ }^{-}$or $\mathrm{ClO}_{4}{ }^{-}$ions. ${ }^{27}$ Furthermore, BArF salts were an attractive option given their adequate solubility profile in solvents that are suitable for AHFs (e.g. toluene containing a small amount of THF).

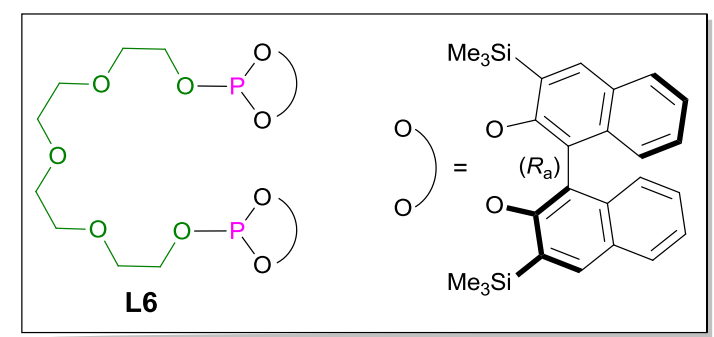

Fig. 6. Supramolecularly regulated ligand for AHFs reported by Vidal-Ferran et al.

As a continuation of their catalytic studies, Vidal-Ferran et al. became interested in evaluating the design principle-namely, whether the addition of an RA in the reaction medium would affect the catalytic activity of the rhodium complexes derived from L6 (Fig. 6). Error! Reference source not found. summarises the effects of different alkali metal and ammonium salts on the catalytic activity. Of all the RAs tested for the AHF of vinyl acetate (S11), RbBArF gave the best results: full conversion, complete regioselectivity (> 99:1 in favour of the branched product) and perfect enantioselectivity ( $99 \%$ ee) were observed (see entry 4 in Error! Reference source not found.). It should be noted that the addition of RbBArF to the reaction mixture had the highest positive regulation effect on the enantioselectivity of the AHF of S11 (enhancement of $64 \%$ in the ee). Interestingly, the use of KBArF or CsBArF rather than RbBArF also provided very high ees (98 and 96\% ee, respectively; see entries 3 and 5 in Error! Reference source not found.). In contrast, when enantiomerically pure ammonium salts RA1 and RA2 were used, the activity of catalysts derived from $\mathbf{L 6}$ worsened. As summarised in Error! Reference source not found., $1 \mathrm{~mol} \%$ of catalyst (a substrate-to-catalyst [S/C] ratio of 100:1) was used for all the assays. Interestingly, the amount of catalyst derived from RbBArF.L6 could be reduced to $0.1 \mathrm{~mol} \%(\mathrm{~S} / \mathrm{C}=1000)$ with almost no decrease in the catalytic activity (99\% conv., b/I ratio > 99:1, and $97 \%$ ee in favour of (S)-P11).$^{28}$ Furthermore, the addition of RbBArF enhanced the catalytic activity of the catalyst as evidenced by a ca. four-fold increase in the reaction 
rate (TOF value with a $\mathrm{S} / \mathrm{C}$ ratio $=1000$ at $50 \%$ conversion (i.e. $\left.\mathrm{TOF}_{1 / 2}\right)$ in

Table 7. Catalytic results obtained for AHFs by Vidal-Ferran et al.

\begin{tabular}{|c|c|c|c|c|c|}
\hline $\mathrm{R}^{\prime}$ & 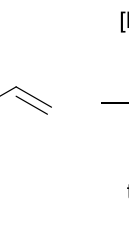 & \multicolumn{2}{|c|}{$\begin{array}{c}\text { RA }(1.56 \mathrm{~mol} \%) \\
10 \text { bar of } 1: 1 \mathrm{CO} / \mathrm{H}_{2} \\
\text { toluene } / \operatorname{THF}(97: 3 \mathrm{v} / \mathrm{v}) \\
40^{\circ} \mathrm{C}\end{array}$} & $\underbrace{\mathrm{CHO}}_{\substack{\text { produc } \\
\text { pranched (b) }}}+$ & linear (I) \\
\hline \multicolumn{2}{|c|}{$\mathrm{S} 11 \mathrm{R}=\mathrm{OCOMe}$} & & & P11 & P12 \\
\hline \multicolumn{2}{|c|}{ S12 R = OCOEt } & & & P13 & P14 \\
\hline \multicolumn{2}{|c|}{ S13 R = OCOPh } & & & P15 & P16 \\
\hline \multicolumn{2}{|c|}{ S14 $R=P h$} & & & P17 & P18 \\
\hline \multicolumn{2}{|c|}{$\mathrm{s} 15 \mathrm{R}=\mathrm{CH}_{2} \mathrm{OSiMe}_{3}$} & & & P19 & P20 \\
\hline Entry & Substrate & RA & $\mathrm{b} / \mathrm{l}$ ratio & $\begin{array}{c}\text { ee } \\
\text { (\%, config.) }\end{array}$ & $\begin{array}{c}\text { Regulation } \\
\text { effects in } \\
\text { ee }(\%)^{a}\end{array}$ \\
\hline 1 & S11 & - & $90: 10$ & $35(S)$ & - \\
\hline 2 & S11 & $\mathrm{NaBArF}$ & $>99: 1$ & $74(S)$ & +39 \\
\hline 3 & S11 & KBArF & $>99: 1$ & $98(S)$ & +63 \\
\hline 4 & S11 & RbBArF & $>99: 1$ & $99(S)$ & +64 \\
\hline 5 & S11 & CsBArF & $>99: 1$ & $96(S)$ & +61 \\
\hline 6 & S11 & RA1 & $>99: 1$ & $40(S)$ & +5 \\
\hline 7 & S11 & RA2 & $>99: 1$ & $40(S)$ & +5 \\
\hline 8 & S12 & - & $96: 4$ & $36(S)$ & - \\
\hline 9 & S12 & $\mathrm{RbBArF}$ & $>99: 1$ & $99(S)$ & +63 \\
\hline 10 & S13 & - & $98: 2$ & $14(S)$ & - \\
\hline 11 & S13 & $\mathrm{RbBArF}$ & $>99: 1$ & $96(S)$ & +82 \\
\hline 12 & S14 & - & $95: 5$ & $12(S)$ & - \\
\hline 13 & S14 & $\mathrm{RbBArF}$ & $80: 20$ & $5(S)$ & -7 \\
\hline 14 & S15 & - & $59: 41$ & $7(S)$ & - \\
\hline 15 & S15 & $\mathrm{RbBArF}$ & $18: 82$ & $25(S)$ & +18 \\
\hline
\end{tabular}

${ }^{a}$ Calculated for each substrate with respect to the experiment in absence of an RA.

the absence of RbBArF $=40 \mathrm{~h}^{-1} ;$ TOF $_{1 / 2}=177 \mathrm{~h}^{-1}$ in the presence of the RA). With regard to the AHF of a wider array of terminal alkenes, the addition of RbBArF significantly enhanced the ees (up to $82 \%$ ) of the AHFs of substrates S12, S13 and S15 (entries 9, 11 and 15 in Error! Reference source not found.) and it also turned out to be the ideal RA for these substrates. Unfortunately, the use of RAs led to lower regio- and enantioselectivities for styrene (S14; compare entries 12 and 13 in Error! Reference source not found.).

Computational studies on the geometry of hydrido-dicarbonyl $\mathrm{Rh}$ (I) complexes derived from $\mathbf{L 6}$ were carried out to gain insight into the structural changes induced by the RA in the catalytic site. These computational studies revealed that the RA had an important effect on the P-Rh-P bond angle of the rhodium complexes (see Fig. 7). ${ }^{29}$ The trend observed was that the size of the ionic radius in the RA cation correlated with the width of the $\mathrm{P}-\mathrm{Rh}-\mathrm{P}$ angle (from $113^{\circ}$, when no RA is present, to $c a .122^{\circ}$ for $\mathrm{K}^{+}, \mathrm{Rb}^{+}$and $\mathrm{Cs}^{+}$). Most interestingly, a plot of the ee in the AHF of vinyl acetate as a function of the $\mathrm{P}-\mathrm{Rh}-\mathrm{P}$ bond angle revealed a maximum in the ee value around the $\mathrm{P}-\mathrm{Rh}-\mathrm{P}$ bond induced by RbBArF, which indicates that the significant increase in the enantiomeric excess resulted from adaptation of the P-Rh-P angle (see Fig. 7). Rhodium complexes derived from $\mathbf{L} 6$ failed to provide good selectivities in the AHF of heterocyclic alkenes, even in the presence of RAs. $^{30 a}$ Ligand $\mathbf{L 7}$ incorporating a $\left(R_{\mathrm{a}}\right)$-BINOL motif at the regulation site and 3,3'-di-tbutyl-[1,1'-biphenyl]-2,2'-diolderived phosphite groups was developed (Fig. 8).Error! Bookmark not defined. ${ }^{b}$

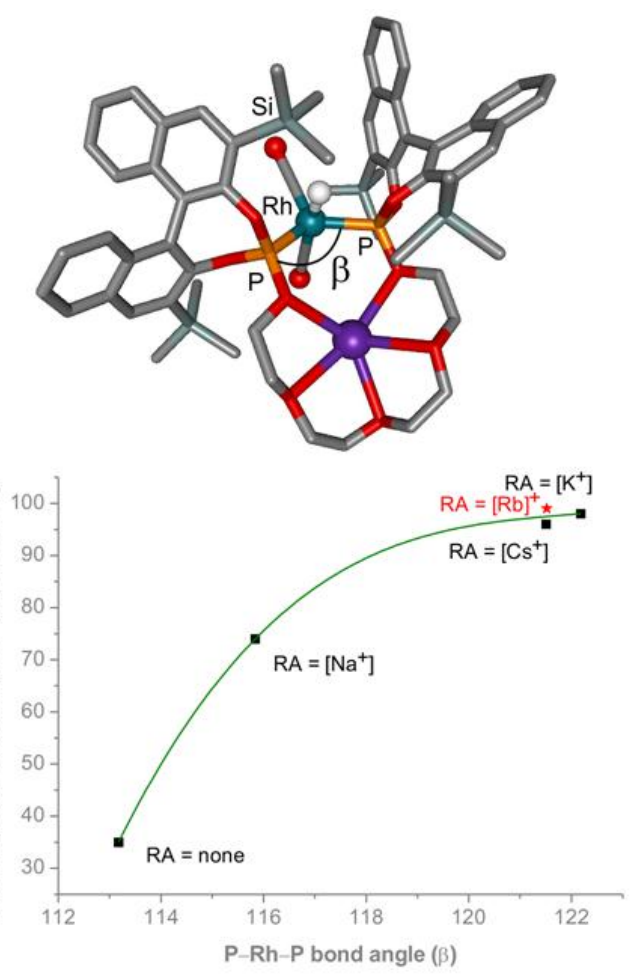

Fig. 7. Rhodium-derived supramolecular complexes and representation of the ee values versus calculated $\mathrm{P}-\mathrm{Rh}-\mathrm{P}$ bond angle value.

Higher enantioselectivities were observed in the AHF of heterocyclic olefins S16, S17 and S18 with L7 than those obtained using L6.Error! Bookmark not defined. ${ }^{a}$ Interestingly, regio- and enantio-selectivities were greatly enhanced by choosing KBArF as the regulation agent. For instance, the AHF of S16 showed full regioselectivity towards product P21 and the use of KBArF as RA improved the conversion (not shown in Table 8Error! Bookmark not defined. ${ }^{b}$ ) and the enantioselectivity (compare entries 1 and 2 in Table 8). The high catalytic activity of the rhodium complexes derived from $\mathbf{L 7}$ and KBArF is reflected in the fact that the AHF of S16 could be performed at room temperature without detrimental effects on the conversion (conv. > 99\%) and with excellent ees ( $93 \%$ ee), which, to the best of our knowledge, is the highest reported for this substrate.Error! Bookmark not defined. ${ }^{b}$ Optimised AHF conditions leading to the highest possible enantioselectivities for products $\mathbf{P 2 2}$ and $\mathbf{P 2 3}$ were identified for dihydrofurans $\mathbf{S 1 7}$ and $\mathbf{S 1 8}$ employing KBArF as the RA (see entries 4 and 6 in Table 8). It is interesting to note that $\alpha$ aldehyde derivative $\mathbf{P 2 2}$ was obtained with higher enantioselectivity than that for its parent $\beta$-aldehyde 
derivative $\mathbf{P 2 3}$ under all studied reaction conditions. The use of KBArF as regulation agent, together with further adjustments of the reaction conditions ( 5 bar of a 1.5:3.5 $\mathrm{CO} / \mathrm{H}_{2}$ gas mixture), allowed the outcome of the reaction to be exquisitely regulated by completely suppressing the formation of the isomerization product of S18 (i.e. S17) and reversing the regioselectivity of the hydroformylation reaction (see entry 8 in Table 8). In short, Vidal-Ferran et al. showed that the inclusion of an enantiopure BINOL motif at the remote site reinforces the regulation ability of the supramolecular catalysts and led to efficient AHF catalysts for a number of heterocyclic olefins.

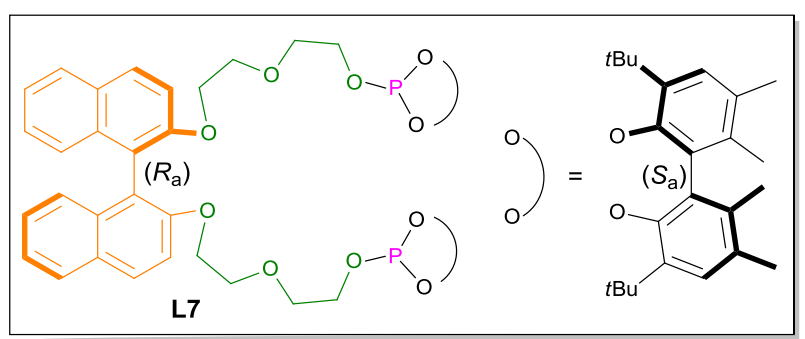

Fig. 8. Supramolecularly regulated ligand for the AHFs of heterocyclic alkenes reported by Vidal-Ferran et al.

Table 8. Catalytic results obtained for AHFs by Vidal-Ferran et $a$ l.<smiles>C1=CCOCOC1</smiles><smiles>O=CC1CCOCOC1</smiles>

s16

$\left[\mathrm{Rh}\left(\kappa^{2} \mathrm{O}, \mathrm{O}^{\prime}-\mathrm{acac}\right)(\mathrm{CO})_{2}\right]$ $(1 \mathrm{~mol} \%)$<smiles>C1=COCC1</smiles>
L7 (1.2 mol\%),

RA (1.56 mol\%) 10 bar of $1: 1 \mathrm{CO} / \mathrm{H}_{2}$ toluene/THF $(97: 3 \mathrm{v} / \mathrm{v})$ $40^{\circ} \mathrm{C}$

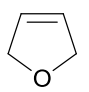

s18

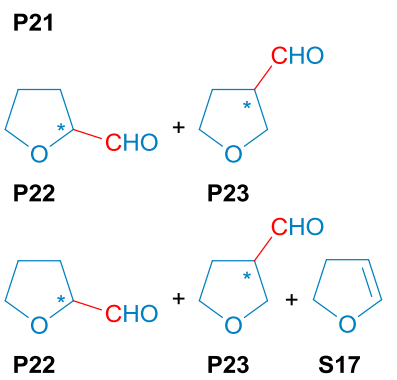

\begin{tabular}{|c|c|c|c|c|c|c|}
\hline Entry & Substrate & RA & $\begin{array}{c}\text { Ratio } \\
\text { P22/P23 }\end{array}$ & $\begin{array}{c}\text { P22+P23 } \\
(\%)\end{array}$ & $\begin{array}{c}\text { ee } \\
(\%, \text { config.) }\end{array}$ & $\begin{array}{c}\text { REs } \\
\text { in ee } \\
(\%)^{a}\end{array}$ \\
\hline $1^{b}$ & S16 & - & & & $10(-)$ & - \\
\hline $2^{b}$ & S16 & KBArF & & & $83(+)$ & +93 \\
\hline \multirow[t]{2}{*}{$3^{c}$} & S17 & - & $1: 1.77$ & 86 & $13(S)$ P22 & - \\
\hline & & & & & $14(S) \mathbf{P 2 3}$ & - \\
\hline \multirow[t]{2}{*}{$4^{c}$} & S17 & $\mathrm{KBArF}$ & $3.65: 1$ & 65 & $84(R)$ P22 & +97 \\
\hline & & & & & rac $\mathbf{P} 23$ & -14 \\
\hline \multirow[t]{2}{*}{$5^{d}$} & S18 & - & $1: 7.33$ & 77 & rac $\mathbf{P 2 2}$ & - \\
\hline & & & & & $33(R) \mathbf{P} 23$ & - \\
\hline \multirow[t]{2}{*}{$6^{d}$} & S18 & KBArF & $1: 1.31$ & 60 & $84(R)$ P22 & +84 \\
\hline & & & & & $62(S)$ P23 & +95 \\
\hline \multirow[t]{2}{*}{$7^{e}$} & S18 & - & $0: 1$ & 83 & - & - \\
\hline & & & & & $29(R) \mathbf{P} 23$ & - \\
\hline \multirow[t]{2}{*}{$8^{e}$} & S18 & $\mathrm{KBArF}$ & $2.45: 1$ & 100 & $74(R)$ P22 & +74 \\
\hline & & & & & $24(S) \mathbf{P} 23$ & +53 \\
\hline
\end{tabular}

${ }^{a}$ Regulation effects (REs) calculated for each substrate with respect to the experiment in absence of an RA. ${ }^{b}$ As indicated in the reaction scheme. ${ }^{c}$ With 5 bar of 3.5:1.5 CO/H ${ }^{d}{ }^{d}$ With 5 bar of $4: 1 \mathrm{CO} / \mathrm{H}_{2}$. ${ }^{e}$ With 5 bar of 1.5:3.5 $\mathrm{CO} / \mathrm{H}_{2}$.

Encouraged by the good levels of regulation and overall performance achieved using polyether-based ligands in AHFs, the same research group shifted their attention to developing supramolecular ligands for asymmetric hydrogenations. ${ }^{27}$ After a ligand screening process, Vidal-Ferran et al. identified the rhodium(I) complexes derived from L8 (Fig. 9) without using a RA (for substrates S3 and S5; see entries 1 and 3 in Table 9) or in combination with ammonium derivative RA1 (for substrates S4, S9 and S19; see entries 2, 4 and 5 in Table 9) or with CsBArF (for substrate S20; see entry 6 in Table 9) as efficient $\mathrm{AH}$ catalysts. As indicated in Table 9, regulation effects in $\mathrm{AH}$ were minor (enhancements of up to $5 \%$ in the ee were observed), as ligand $\mathbf{L 8}$ already provided very high enantioselectivities. However, the use of RAs served to slightly improve enantioselectivities by adapting the catalysts derived from $\mathbf{L} \mathbf{8}$ to the geometry of the different substrates.

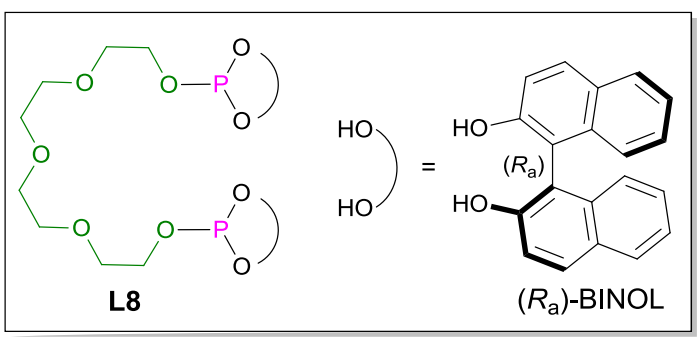

Fig. 9. Supramolecularly regulated ligand for AHs reported by Vidal-Ferran et al. 
Table 9. Catalytic results obtained for AHs by Vidal-Ferran et al.

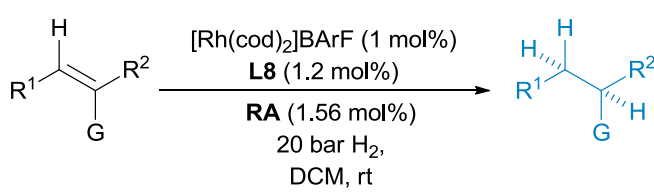

\begin{tabular}{lllll} 
& $\mathrm{R}^{1}$ & $\mathrm{R}^{2}$ & $\mathrm{G}$ & \\
\hline S3 & $\mathrm{H}$ & coOMe, & $\mathrm{CH}_{2}$ COOMe & P3 \\
S4 & $\mathrm{H}$ & COOMe, & NHAc & P4 \\
S5 & $\mathrm{Ph}$ & COOMe & NHAc & P5 \\
S9 & $\mathrm{H}$ & $\mathrm{Ph}$ & $\mathrm{NHAc}$ & P9 \\
S19 & $\mathrm{Ph}$ & coOMe & $\mathrm{CH}_{2} \mathrm{NHAc}$ & P24 \\
S20 & $\mathrm{H}$ & 1-Naphth & NHAc & P25
\end{tabular}

\begin{tabular}{ccccc}
\hline Entry & Substrate & RA & $\begin{array}{c}\text { ee } \\
(\%, \text { config. })\end{array}$ & $\begin{array}{c}\text { Regulation } \\
\text { effects in } \\
\text { ee }(\%)^{a}\end{array}$ \\
\hline 1 & S3 & - & $97(R)^{b}$ & - \\
2 & S4 & RA1 & $96(S)$ & +2 \\
3 & S5 & - & $92(S)^{b}$ & - \\
4 & S9 & RA1 & $93(S)$ & +3 \\
5 & S19 & RA1 & $95(S)$ & +2 \\
6 & S20 & CsBArF & $78(R)$ & +5
\end{tabular}

${ }^{a}$ Calculated for each substrate with respect to the experiment in absence of an RA. ${ }^{b}$ The highest ees were obtained in the absence of an RA.

As a continuation of their efforts in developing supramolecularly regulated enantioselective catalysts, Fan and He et al. described the first example of a regulated catalyst for asymmetric Henry reactions. ${ }^{31}$ The designed catalyst was derived from enantiopure ligand $\mathbf{L} \boldsymbol{9}$ and contained two chromium(III)-salen moieties (salen $=2,2^{\prime}-\left(\left(1 E, 1^{\prime} E\right)\right.$-(ethane1,2-diylbis(azanylylidene))bis(methanylylidene))diphenol; see the red fragment in Fig. 10) separated by a polyether chain. Fan and $\mathrm{He}$ et al. envisaged that supramolecular interactions between the polyether chain of the $\alpha, \omega$-bis(metallosalen) derivative and a regulation agent (RA) would bring the two chromium(III)-salen units together and convert the resulting supramolecular

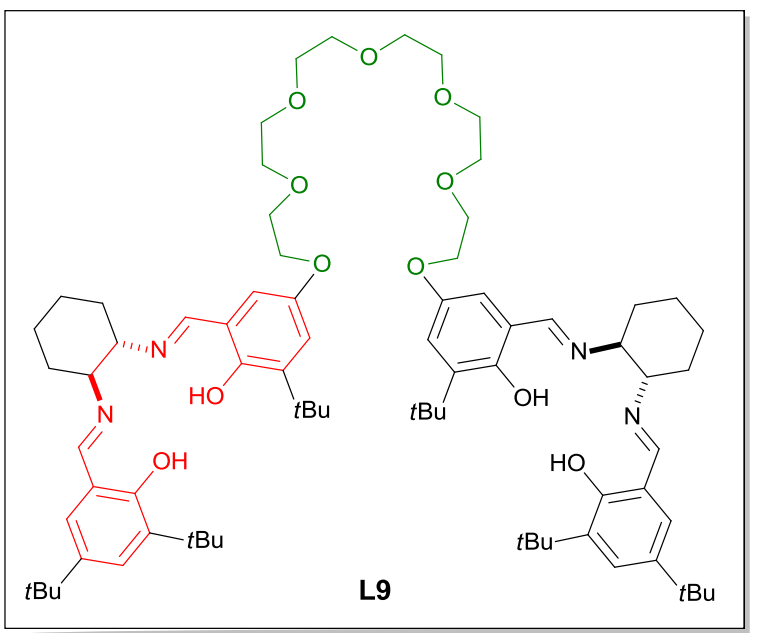

Fig. 10. Supramolecularly regulated ligand for asymmetric Henry reactions reported by Fan and He et al.
Table 10. Catalytic results obtained for asymmetric Henry reactions by Fan and $\mathrm{He}$ et al.

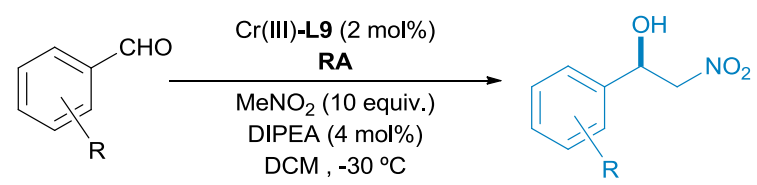

S21 $\mathrm{R}=\mathrm{OMe}, \mathrm{Br}, \mathrm{F}, \mathrm{Cl}$

$\mathrm{P} 26 \mathrm{R}=\mathrm{OMe}, \mathrm{Br}, \mathrm{F}, \mathrm{Cl}$

\begin{tabular}{|c|c|c|c|c|}
\hline Entry & Substrate & $\begin{array}{c}\text { RA } \\
\text { (mol\%) }\end{array}$ & ee $(\%)$ & $\begin{array}{l}\text { Regulation } \\
\text { effects in } \\
\text { ee }(\%)^{a}\end{array}$ \\
\hline 1 & S21, $\mathrm{R}=2-\mathrm{OMe}$ & - & 87 & - \\
\hline 2 & S21, $R=2-O M e$ & LiBArF (2) & 89 & +2 \\
\hline 3 & S21, $R=2-O M e$ & $\mathrm{NaBArF}(2)$ & 89 & +2 \\
\hline 4 & S21, $R=2-O M e$ & KBArF (2) & 91 & +4 \\
\hline 5 & S21, $R=2-O M e$ & CsBArF (2) & 89 & +2 \\
\hline 6 & S21, $R=2-O M e$ & KBArF (1) & 90 & +3 \\
\hline 7 & S21, $R=2-O M e$ & KBArF (4) & 93 & +6 \\
\hline 8 & S21, $R=2-B r$ & - & 77 & - \\
\hline 9 & S21, $R=2-B r$ & KBArF (4) & 86 & +9 \\
\hline 10 & $S 21, R=2-F$ & - & 81 & - \\
\hline 11 & $S 21, R=2-F$ & KBArF (4) & 90 & +9 \\
\hline 12 & $S 21, R=2-C l$ & - & 80 & - \\
\hline 13 & $S 21, R=2-C l$ & KBArF (4) & 96 & +16 \\
\hline 14 & S21, $R=3-O M e$ & - & 53 & - \\
\hline 15 & S21, $R=3-O M e$ & KBArF (4) & 84 & +31 \\
\hline 16 & S21, $\mathrm{R}=3-\mathrm{Cl}$ & - & 66 & - \\
\hline 17 & S21, $\mathrm{R}=3-\mathrm{Cl}$ & KBArF (4) & 84 & +18 \\
\hline 18 & S21, $R=4-F$ & - & 77 & - \\
\hline 19 & S21, $R=4-F$ & KBArF (4) & 85 & +8 \\
\hline 20 & $S 21, R=4-C l$ & - & 74 & - \\
\hline 21 & $S 21, R=4-C l$ & KBArF (4) & 83 & +9 \\
\hline
\end{tabular}

${ }^{a}$ Calculated for each substrate with respect to the experiment in absence of an RA.

complex into a suitable catalyst for transformations involving a bimetallic cooperative catalysis mechanism, such as asymmetric Henry reactions. Initially, the authors studied the binding of KBArF, as a representative RA, to the polyether chain of $\mathbf{L} 9$ and measured an association constant $K=79 \pm 12$ $\mathrm{M}^{-1}$ in $\mathrm{CDCl}_{3}$ for a $1: 1$ binding process. The authors then assessed the new catalyst in a benchmark asymmetric Henry reaction using 2-methoxybenzaldehyde as a model substrate and a set of alkali metal BArF salts as RAs. As reflected in Table 10 , the size of the cation affected the catalytic activity with the best results in terms of activity and enantioselectivity being obtained with KBArF as the RA (compare entries 2-5 in Table 10). Moreover, by increasing the amount of KBArF to two equivalents with respect to the amount of the $\alpha, \omega$ bis(metallosalen) derivative, almost complete conversion and an enhancement of up to $6 \%$ in the ee were observed (compare entries 4, 6 and 7 in Table 10). With the optimised reaction conditions in hand, Fan and He et al. expanded the substrate scope of the reaction to an array of differently substituted aromatic aldehydes. This study revealed that the highest regulation effects in terms of both conversion and enantioselectivity were observed for the meta-substituted benzaldehydes (see entries 14-17 in Table 10; positive regulation effects of up to $31 \%$ in the ee). 
More recently, Vidal-Ferran et al. have used supramolecularly regulated catalysts in asymmetric allylic substitutions (AASs). ${ }^{32}$ These authors envisaged that the combination of metal salts, which could function both for the generation of the required nucleophiles and for triggering the regulation mechanism, with palladium complexes derived from the previously developed ligands could mediate AASs. Initial catalytic studies aimed to identify the optimal palladium precursor and ligand for this chemistry on model substrate $\mathbf{S 2 2}$ (Fig. 11 and Table 11). ${ }^{28}$ of all the combinations tested, $\mathrm{RbOAc} \bullet(e n t-\mathrm{L} 8)$ and $\left[\mathrm{PdCl}_{2}(\mathrm{cod})\right]$ gave the best results in the AAS of substrate $\mathbf{S 2 2}$ with dimethyl malonate (DMM); that is full conversion and $65 \%$ ee (increase of $6 \%$ ee with respect to when no RA was used; compare entries 1-10 in Table 11). The AAS of cinnamyl acetate S23 with DMM could also be supramolecularly regulated by employing ligand $\mathbf{L 1 0}$ and $\left[\mathrm{Pd}(\mu-\mathrm{Cl})\left(\eta^{3}-\mathrm{C}_{3} \mathrm{H}_{5}\right)\right]_{2}$ to achieve the highest enantioselectivity or the same catalytic system in the presence of $\mathrm{Mg}(\mathrm{OTf})_{2}$ to slightly improve the $\mathrm{b} / \mathrm{l}$ ratio in favour of the branched compound P28 (compare entries 11 and 12 in Table 11). The outcome of the allylic amination of substrate $\mathbf{S 2 2}$ was also supramolecularly regulated using a similar approach. A low ee was obtained for benzylamine (BZA) as the nucleophile when no RAs were used (see entry 13 in Table 11). In contrast with the results observed with the C-nucleophile, ${ }^{32}$ an improvement in the ee was observed by using group II or lanthanide triflates as RAs (see entry 14 in Table 11).

In short, it has been described in this section how combinations of RAs and polyether based-ligands have been used to supramolecularly regulate the outcome of AHs, AHFs, asymmetric Henry reactions and AASs. The achievements summarised in this section demonstrate that this strategy can be used to easily prepare libraries of enantiopure supramolecular ligands (or catalytic systems). Furthermore, appropriate combinations of ligands plus the corresponding regulation agents provided enantioselective catalysts that adapted to the specific geometry of the substrate of interest in a given transformation.

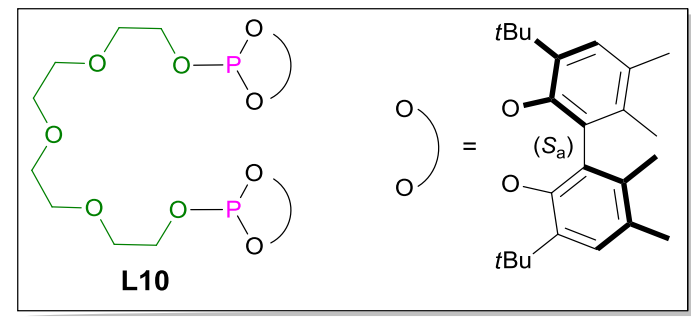

Fig. 11. Supramolecularly regulated ligand for AASs reported by Vidal-Ferran et al.
Table

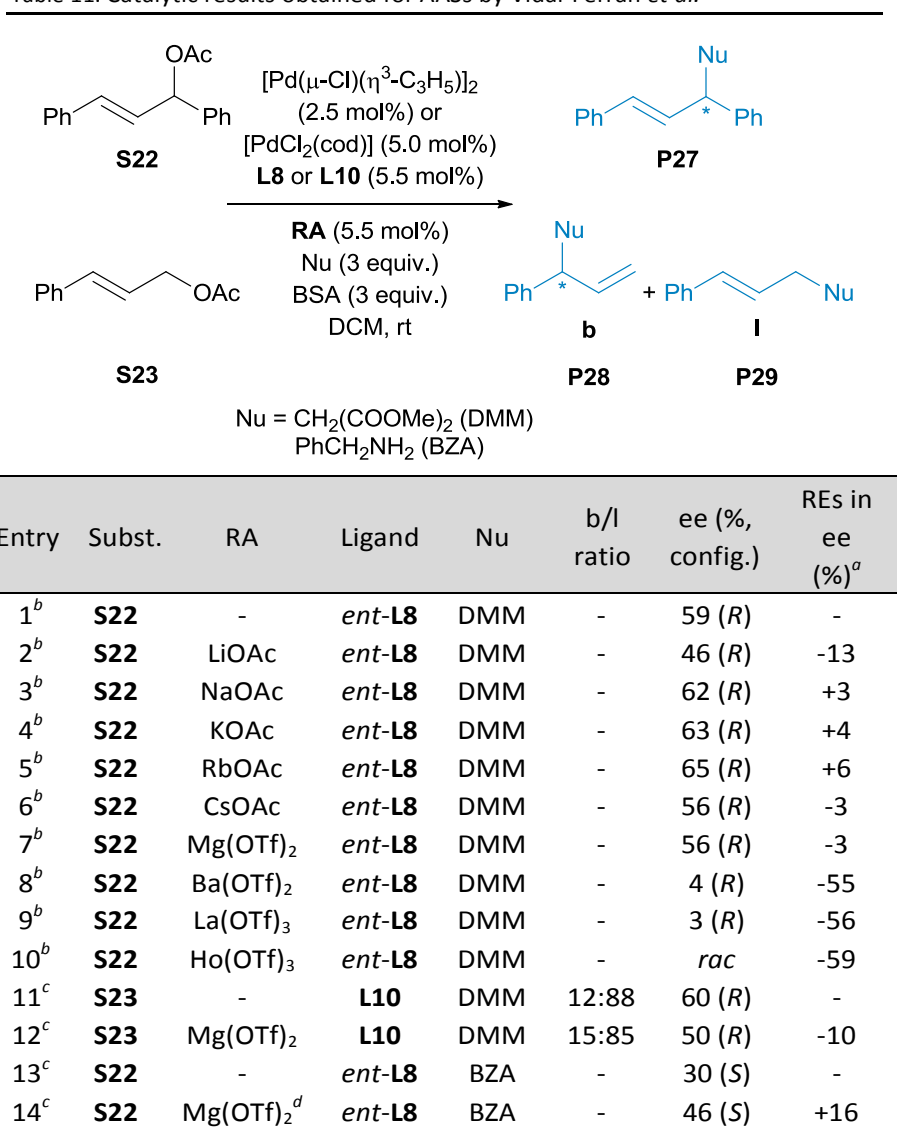

${ }^{a}$ Regulation effects (REs) calculated for each substrate with respect to the experiment in absence of an RA. ${ }^{b}\left[\mathrm{PdCl}_{2}(\operatorname{cod})\right]$ as precursor. ${ }^{c}\left[\mathrm{Pd}(\mu-\mathrm{Cl})\left(\eta^{3}-\mathrm{C}_{3} \mathrm{H}_{5}\right)\right]_{2}$ as precursor. ${ }^{d} \mathrm{Ba}(\mathrm{OTf})_{2}, \mathrm{La}(\mathrm{OTf})_{3}$ and $\mathrm{Ho}(\mathrm{OTf})_{3}$ had the same regulation effects.

2.1.3. Catalytic systems containing complementary hydrogen-bonding motifs. Clarke and co-workers designed a supramolecularly regulated enantioselective catalyst formed by complementary hydrogen bonding between a first unit, containing a substituted pyrrolidine ring responsible for enantioselective catalysis (see $\mathbf{L 1 1}$ and $\mathbf{L 1 2}$ in Fig. 12), and a second unit bearing an achiral additive to influence the steric environment at the catalytic site (see the 1 - $(1 \mathrm{H}$-imidazol-2yl)urea-containing structures RA3 and RA4 in Fig. 12). Furthermore, this example is highly interesting because it illustrates that supramolecular regulation strategies are not limited to transition-metal catalysed reactions and can also be used for organocatalysed processes such as the asymmetric Michael addition of ketones to nitroalkenes. ${ }^{33}$ Clarke et al. envisaged that enantiopure amidonaphtyridine motifs (present in structures $\mathbf{L 1 1}$ and L12) and 3-substituted 1-(1H-imidazol-2yl)urea structures (present in RA3 and RA4) would be highly complementary recognition motifs through hydrogen-bonding interactions. Thus, they were chosen as the complementary units for achieving precise self-assembly by hydrogen bonding towards the target supramolecular catalysts (Fig. 12). ${ }^{33}$ Clarke et al. observed that supramolecular assemblies arising from the combination of ligands L11 or L12 and regulation agents RA3 and RA4 were more efficient in mediating asymmetric Michael reactions than catalysts $\mathbf{L 1 1}$ or $\mathbf{L 1 2}$ alone (compare 
entries 1 with 2 and 5 with 6 in Table 12). For asymmetric Michael additions of cyclohexanone S24 to nitroalkene S26, an important enhancement in the diastereoselectivity (from a $26: 1$ to a $65: 1$ ratio in favour of the syn diastereoisomer) and enantioselectivity (from 6 to $68 \%$ ee, compare entries 1 and 2 in Table 12) of the reaction was observed when the hydrogenbonding complementary regulation agent RA3 was used.

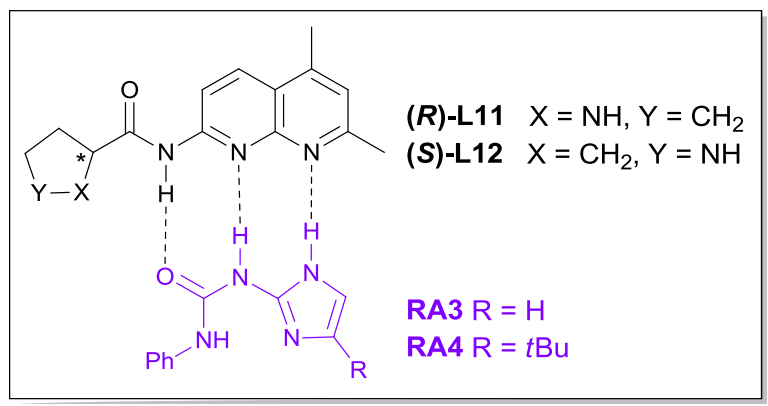

Fig. 12. Supramolecularly regulated catalysts for asymmetric Michael additions reported by Clarke et al.

Interestingly, a slightly modified regulation agent (the 4substituted 1-(1H-imidazol-2-yl)urea RA4) achieved the highest diastereo- and enantio-selectivities in the asymmetric Michael additions of cyclohexanone $\mathbf{S 2 4}$ to (E)-(2-nitrovinyl)benzenes with substituents at the phenyl ring (S27 and S28; see entries 3 and 4 in Table 12). Asymmetric Michael additions of acyclic aliphatic aldehyde S25 to nitroalkene S26 required the combination of the regulation agent RA3 and a new aminocontaining unit $((S)$-L12) as opposed to the original prolinecontaining one $((R)$-L11) (see structures in Fig. 12). Acceptable diastereoselectivities were obtained using the catalyst derived from the aforementioned self-complementary units for hydrogen bonding. Unfortunately, the final product obtained was a racemic mixture (see entries 5 and 6 in Table 12).

Table 12. Catalytic results obtained for asymmetric Michael additions by Clarke et al.

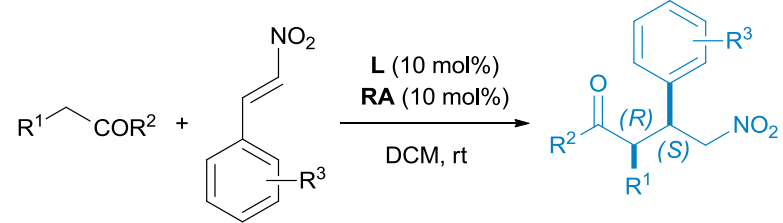

(major (syn) stereoisomer formed)

S24 $R^{1}, R^{2}=\quad S 26 R^{3}=H$

$\left(-\mathrm{CH}_{2}-\right)_{4} \quad \mathrm{~S} 27 \mathrm{R}^{3}=4-\mathrm{MeO}$

$\mathrm{S} 25 \mathrm{R}^{1}=n \mathrm{Bu}, \quad \mathrm{S} 28 \mathrm{R}^{3}=3-\mathrm{NO}_{2}$ $\mathrm{R}^{2}=\mathrm{H}$

P30 R $1, \mathrm{R}^{2}=\left(-\mathrm{CH}_{2}-\right)_{4}, \mathrm{R}^{3}=\mathrm{H}$

P31 R $\mathrm{R}^{1}, \mathrm{R}^{2}=\left(-\mathrm{CH}_{2}-\right)_{4}, \mathrm{R}^{3}=4-\mathrm{MeO}$

P32 $R^{1}, R^{2}=\left(-\mathrm{CH}_{2}-\right)_{4}, \mathrm{R}^{3}=3-\mathrm{NO}_{2}$

P33 $\mathrm{R}^{1}=n \mathrm{Bu}, \mathrm{R}^{2}=\mathrm{H}, \mathrm{R}^{3}=\mathrm{H}$

\begin{tabular}{ccccccc}
\hline Entry & Substrates & Catalyst & $\begin{array}{c}\text { Conv. } \\
(\%)\end{array}$ & $\mathrm{dr}^{a}$ & $\begin{array}{c}\text { ee }^{b} \\
(\%, \text { config. })\end{array}$ & $\begin{array}{c}\text { REs in } \\
\text { ee }(\%)^{c}\end{array}$ \\
\hline 1 & S24, S26 & $(R)$-L11, - & 87 & $26: 1$ & $6(R, S)$ & - \\
2 & S24, S26 & $(R)$-L11, RA3 & 99 & $65: 1$ & $68(R, S)$ & +62 \\
3 & S24, S27 & $(R)$-L11, RA4 & 47 & $36: 1$ & $74(R, S)$ & - \\
4 & S24, S28 & $(R)$-L11, RA4 & 41 & $7: 1$ & $81(R, S)$ & - \\
5 & S25, S26 & $(S)$-L12, - & $<5$ & n.d. & n.d. & - \\
6 & S25, S26 & $(S)$-L12, RA3 & 95 & $12: 1$ & rac & n.d.
\end{tabular}

${ }^{a}$ syn:anti ratio. ${ }^{b}$ ee of the syn product. The first stereochemical descriptor refers to the carbon alpha to the $\mathrm{C}=\mathrm{O}$ group and the second to the aryl-substituted one. ${ }^{c}$ Regulation effects (REs) calculated for each substrate with respect to the experiment in absence of an RA.

\subsection{Supramolecular regulation on a pro-chiral ligand}

The principle of this approach is similar to that detailed in the previous section: a regulation agent is employed to modify the geometry of the catalytic site. However, the three-dimensional structure of the catalytic site is not well defined in the absence of the regulation agent and, upon addition of an enantiopure regulation agent, chirogenesis processes mediated by the RA lead to an asymmetric supramolecular assembly with a welldefined three-dimensional structure. Reek et al. have published the only examples of this elegant approach for generating libraries of enantioselective supramolecular catalysts. ${ }^{34,35}$ These authors have shown that the interaction of an enantiopure regulation agent (called a "cofactor" by the authors) with an achiral bisphosphine or bisphosphite metal complex equipped with a binding site to recognise the RA, efficiently led to the formation of an asymmetric supramolecular assembly that was used as pre-catalyst in $\mathrm{AHs}^{34}$ or AASs. ${ }^{35}$ With regard to the first asymmetric transformation, initial studies aimed to identify a suitable strategy that would facilitate the straightforward preparation of libraries of enantioselective catalysts from ligand L13 (see Fig. 13). This ligand contained a diamidodiindolylmethane motif (as the binding site for the regulation agent) and phosphine binding groups for the generation of rhodium catalysts for $\mathrm{AH}$. Reek et al. demonstrated that cationic ligandrhodium complexes $[\mathrm{Rh}(\mathrm{nbd})(\mathbf{L 1 3})]^{+}$were straightforwardly formed by mixing stoichiometric amounts of ligand L13 and the standard cationic rhodium precursor for AHs (i.e. $\left.\left[\mathrm{Rh}(\mathrm{nbd})_{2}\right] \mathrm{BF}_{4}\right) .{ }^{34}$ Interestingly, the $\mathrm{X}$-ray structure of the resulting complexes $[\mathrm{Rh}(\mathrm{nbd})(\mathbf{L} 13)] \mathrm{BF}_{4}$ showed that in the solid state the $\mathrm{BF}_{4}^{-}$anion was bound to the ligand's diamidodiindolylmethane motif, which acted as an efficient receptor for this anion. Binding studies in solution demonstrated that the $\mathrm{BF}_{4}^{-}$anion was easily displaced by regulation agents (or cofactors) with carboxylate groups, as these proved to have a much higher affinity for the diamidodiindolylmethane motif than the $\mathrm{BF}_{4}{ }^{-}$anion. The authors exploited the high affinity of carboxylate anions towards the diamidodiindolylmethane motif in ligand L13 $K>$ $10^{5} \mathrm{M}^{-1}$ in dichloromethane) and the wide availability of enantiomerically pure compounds containing a carboxylate group to easily generate libraries of supramolecular enantioselective catalysts using this strategy. ${ }^{34}$ Detailed NMR studies confirmed chirogenesis in the supramolecular binding event (i.e. chirality transfer from the regulation agent to the 
carbon backbone of the rhodium complex through supramolecular interactions). Subsequent studies aimed to identify the optimal regulation agent that mediated the highest enantioselectivity in the $\mathrm{AH}$ of functionalised alkenes. The authors studied ${ }^{34}$ a wide variety of enantiopure carboxylate-containing derivatives in the $\mathrm{AH}$ of $\alpha$ acylaminoacrylate S4 (see entry 1 in Table 13), with amino acid derivatives as RAs providing the best results in terms of ees. Reek et al. identified the substituents at the nitrogen group of the amino acid derivative as the structural motif of the regulation agent that had the greatest effect on the ees of the $\mathrm{AH}$, whereas varying the side chain of the amino acid derivative had a smaller influence. ${ }^{34}$ The valine-derived RA RA5, which incorporates a tbutylthiourea group at the nitrogen group, was identified after an iterative deconvolution catalyst screening strategy as the optimal RA for providing the highest ees in the AH of $\alpha$-acylaminoacrylate S4 (full conversion, 98\% ee; entry 1 in Table 13). In an analogous manner, the same regulation agent mediated the $\mathrm{AH}$ of $\alpha$ acylaminoacrylate $\mathbf{S 2 9}$, arylenamide $\mathbf{S 9}$, itaconic acid derivative S3 and 2-methylenepentanedioic acid derivative S32 (ees ranging from 39 to $91 \%$ ee; see entries 2, 3, 6, and 7 in Table 13 , respectively) with the highest ees. In contrast, valine derivative RA6, which incorporates a tbutylcarbamoyl group at the nitrogen group, was the RA of choice for the AH of dihydronaphthalenyl acetamides S30 and S31 (see entries 4 and 5 in Table 13).
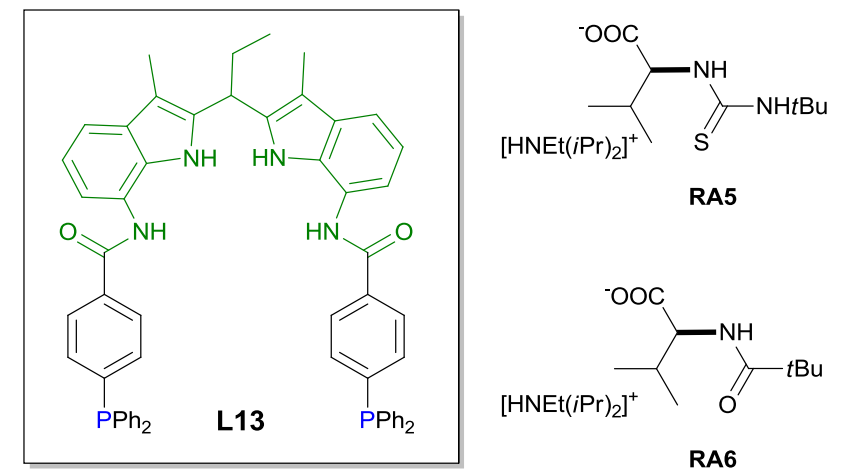

Fig. 13. Supramolecularly regulated ligand and RAs by AH from Reek et al.

Following the same regulation strategy, Reek, Moberg et al. described the application of the new bisphosphite ligand L14 to palladium-mediated AASs; see Error! Reference source not found. and Error! Reference source not found. ${ }^{35}$ The addition of an enantiopure acid derivative as the RA (or "cofactor" as referred to by the authors) broke the symmetry of the diamidodiindolylmethane fragment in ligand L14 and generated preferred conformations in the conformationally labile phosphite groups. NMR spectroscopy studies showed that hydrogen bonding between the NH groups in ligand L14 and the oxyanions was at the origin of the chirogenesis processes taking place. A mixture of ligand L14 and an excess of the enantiopure RAs (RA7 and RA8; see Error! Reference source not found.) led to a splitting of the phosphorus and $\mathrm{NH}$ signals in the ${ }^{31} \mathrm{P}\left\{{ }^{1} \mathrm{H}\right\}$ and ${ }^{1} \mathrm{H}$ NMR spectra, respectively. The presence of a major group of signals in the above mentioned
NMR spectra was attributed to a preferred stabilisation of one of the two possible configurations of the carbon between the two indole rings and one of those possible for the phosphite groups. ${ }^{35}$ Catalysts derived from ligand $\mathbf{L 1 4}$ and $\left[\mathrm{Pd}(\mu-\mathrm{Cl})\left(\eta^{3}\right.\right.$ $\left.\left.\mathrm{C}_{3} \mathrm{H}_{5}\right)\right]_{2}$ were applied to AASs on substrates S33 and S34 (see the Scheme to Error! Reference source not found.). The authors observed the formation of enantioenriched products when enantiopure RAs were used. The substrates S33 and \$34 were chosen as model substrates for the catalytic studies given the different ligand requirements for achieving high ees in the AASs on these two substrates: substrate $\mathbf{S 3 3}$ requires ligands with pseudo- $C_{2}$ symmetry, whilst ligands with pseudo- $C_{s}$ symmetry mediate AASs on $\mathbf{S 3 4}$ with higher ees. A library of enantiopure acid derivatives was tested, ${ }^{35}$ from which RA7 and RA8 provided the highest enantioselectivities. When dimethylmalonate (DMM) was used, higher conversions and ees were obtained by employing RA7 for the AASs on S33 (57\% ee, compare entries 1 and 2 in Error! Reference source not found.). In contrast, higher regulation effects in the AASs on S34 were obtained using RA8 (compare entries 3 and 4 in Error! Reference source not found.). The highest ee was obtained for S33 when benzylamine (BZA) was used as the nucleophile and

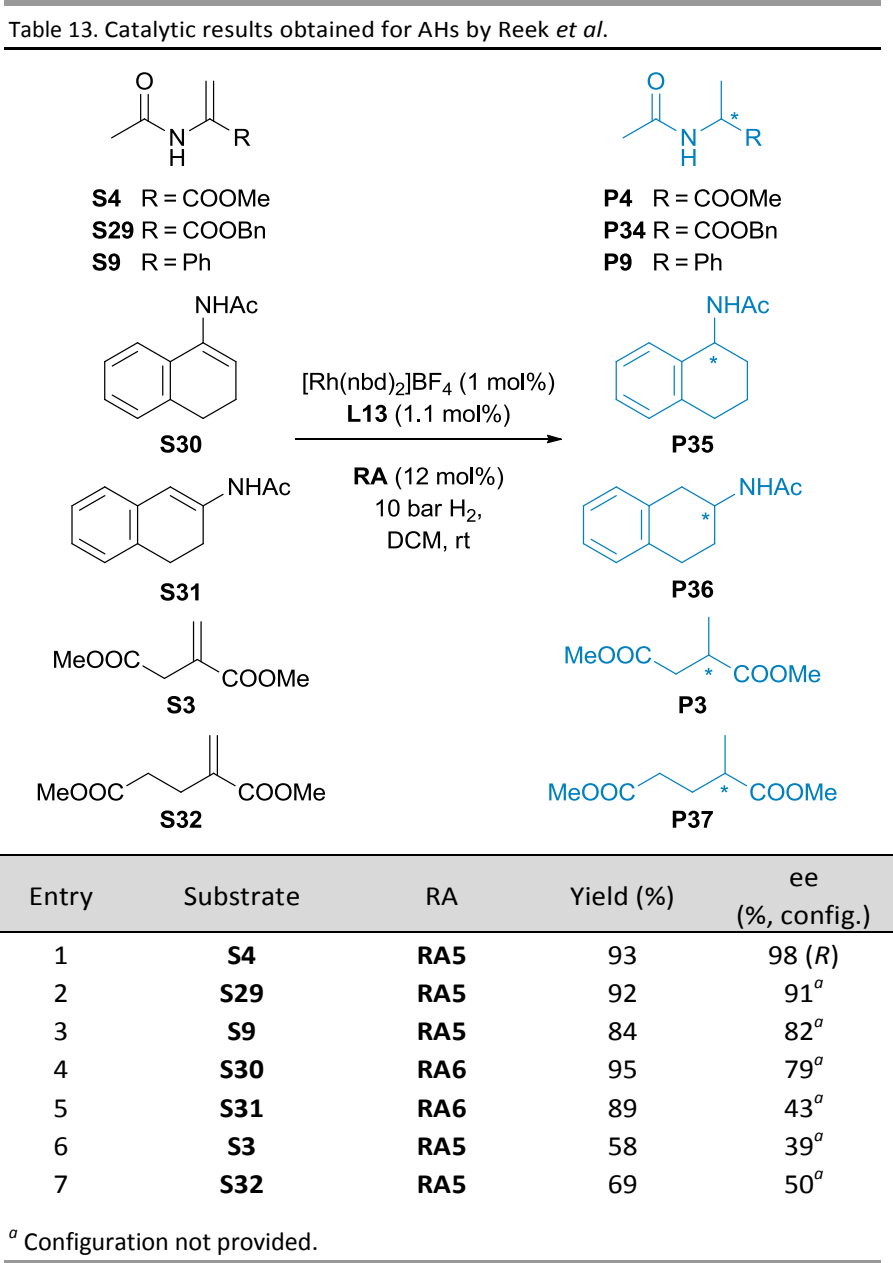

RA7 (66\% ee, entry 5 in Error! Reference source not found.), but the AASs product derived from S34 and BZA was obtained with low levels of enantioselectivity when either RA7 or RA8 
was employed (see entries 7 and 8 in Error! Reference source not found.).

In short, Reek's ${ }^{34}$ and Reek's \& Moberg's ${ }^{35}$ elegant approaches for regulating the catalyst activity and stereoselectivity demonstrate that efficient AH or AAS catalysts can be easily obtained by the optimal choice of an enantiomerically pure RA and achiral ligands L13 or L14, respectively.

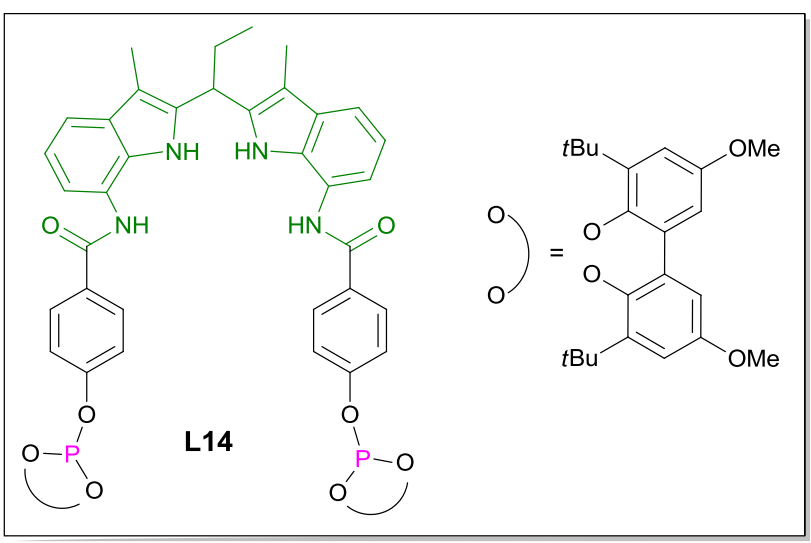

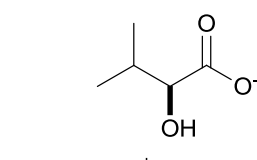

$\left[\mathrm{HNEt}(i \mathrm{Pr})_{2}\right]^{+}$

RA7

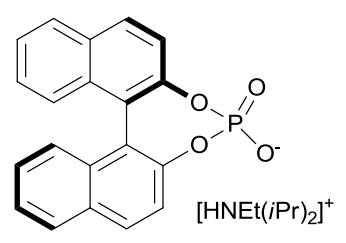

RA8
Fig. 14. Supramolecularly regulated ligand and RAs for AASs reported by Reek and Moberg et al.
Table 14. Catalytic results obtained for AASs by Reek and Moberg et al.

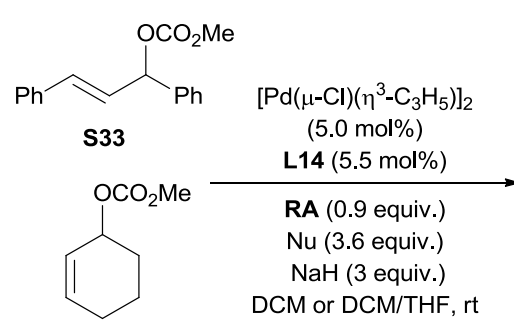

S34

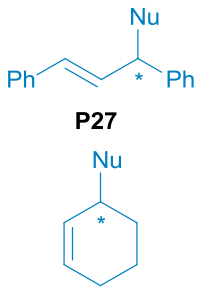

P38
$\mathrm{Nu}=\mathrm{CH}_{2}(\mathrm{COOMe})_{2}(\mathrm{DMM})$

$\mathrm{PhCH}_{2} \mathrm{NH}_{2}$ (BZA)

\begin{tabular}{cccccc}
\hline Entry & Substrate & RA & Nu & Yield (\%) & $\begin{array}{c}\text { ee } \\
\text { (\%, config.) }\end{array}$ \\
\hline 1 & S33 & RA7 & DMM & 97 & $57(S)$ \\
2 & S33 & RA8 & DMM & 89 & $39(R)$ \\
3 & S34 & RA7 & DMM & 94 & $5(S)$ \\
4 & S34 & RA8 & DMM & 73 & $43(R)$ \\
5 & S33 & RA7 & BZA & 85 & $66(R)$ \\
6 & S33 & RA8 & BZA & 87 & $57(S)$ \\
7 & S34 & RA7 & BZA & 85 & $4(R)$ \\
8 & S34 & RA8 & BZA & 89 & $12(S)$ \\
\hline
\end{tabular}

\section{Conclusions and outlook}

This feature article highlights different supramolecular strategies for generating a set of enantioselective catalysts that retain most of the backbone's structural features yet at the same time incorporate subtle changes at their active sites that are determined by the structural characteristics of the external molecule (or regulation agent) that is employed. Two different categories of supramolecularly fine-regulated enantioselective catalytic systems have been developed.

The first type of catalytic system possesses a catalytic site with a well-defined three-dimensional structure suitable for enantioselective catalysis and a distal regulation site containing a supramolecular motif capable of interacting with the regulation agent. The interaction between cyclic (aza)crown-ether, metallacrown-ether and polyether supramolecular motifs with metal salts or ammonium derivatives as RAs has been exploited by a number of research groups for generating libraries of enantioselective catalysts, which are capable of geometric adaptation to the requirements of a given substrate for high enantioselectivity in asymmetric hydrogenations, hydroformylations, Henry reactions and allylic substitutions on an array of structurally diverse substrates. This regulation concept at the active site of the enantioselective catalyst has not been restricted to transition metal-based transformations, such as those previously mentioned. Researchers have also developed supramolecularly regulated enantioselective organocatalysts for asymmetric Michael addition reactions. In this case, the regulation agent is attached to the unit that contains the catalytic site by a highly efficient and precise hydrogenbonding-mediated assembly process.

The second type of supramolecularly fine-regulated catalytic system is directly generated from a pro-chiral unit containing the catalytic site. The three-dimensional structure of the catalytic site is not well-defined in the absence of a regulation agent, and in this elegant approach, the addition of an enantiopure regulation agent triggers chirogenesis processes from the regulation agent to the carbon backbone containing the catalytic site. In this case, the authors demonstrated that efficient asymmetric hydrogenation and allylic substitution catalysts could be obtained with unprecedented ease just by the optimal choice of an enantiopure regulation agent (or "cofactor" as referred to by the authors).

The approaches reported in the present article for the fineregulation of the activity of an enantioselective catalyst combine concepts from supramolecular and physical organic chemistry with traditional approaches from enantioselective catalysis. The potential for research and innovation is almost unlimited, with ample scope for the development of practical applications. Thus, one can only imagine that the near future will witness new examples of successful application of fineregulation strategies to new enantioselective catalysts for transformations of interest.

\section{Acknowledgements}


The authors would like to thank MINECO (CTQ2014-60256-P and Severo Ochoa Excellence Accreditation 2014-2018 SEV2013-0319) and the ICIQ Foundation for financial support. Dr. $M$. V. is grateful for the financial support received from the CELLEX Foundation. L. R. thanks ICIQ for a pre-doctoral fellowship. Dr. Héctor Fernández-Pérez is gratefully acknowledged for proof-reading the manuscript and Dr. José Luis Núñez-Rico for his support in the preparation of a few graphics.

\section{Notes and references}

1 For general references on this topic, see for example: (a) Comprehensive Asymmetric Catalysis, eds. E. N. Jacobsen, A. Pfaltz and H. Yamamoto, Springer-Verlag, Heidelberg, 1st edn., 1999, vol. I-III. (b) Comprehensive Chirality, eds. E. M. Carreira and H. Yamamoto, Elsevier Science, Oxford, 2012, vol. 1-9.

2 In biocatalysis these two roles are played by the biocatalyst (i.e. enzyme).

3 Chiral pool refers to the stock of readily available enantiopure natural products.

4 Privileged Chiral Ligands and Catalysts, ed. Q.-L. Zhou, Wiley-VCH, Weinheim, Germany, 2011.

5 Any catalytic event involves supramolecular interactions, as the catalytic system recognizes substrates and reagents, and organizes them in a certain arrangement. Within this article, the concept supramolecular catalysis does not refer to those situations but it is employed when the supramolecular interactions do not form part of the catalytic event.

6 See, for example: (a) B. Breit, Angew. Chem., Int. Ed. 2005, 44, 6816; (b) R. Kraemer, Angew. Chem., Int. Ed. 2006, 45, 858; (c) C. Letondor and T. R. Ward, ChemBioChem, 2006, 7, 1845; (d) P. E. Goudriaan, P. W. N M. van Leeuwen, M.-N. Birkholz and J. N. H. Reek, Eur. J. Inorg. Chem., 2008, 2939; (e) A. J. Boersma, R. P. Megens, B. L. Feringa and G. Roelfes, Chem. Soc. Rev., 2010, 39, 2083; (f) R. M. Haak, S. J. Wezenberg and A. W. Kleij, Chem. Commun., 2010, 46, 2713; (g) L. A. Joyce, S. H. Shabbir and E. V. Anslyn, Chem. Soc. Rev., 2010, 39, 3621; (h) J. Meeuwissen and J. N. H. Reek, Nat. Chem., 2010, 2, 615; (i) F. Rosati and G. Roelfes, ChemCatChem, 2010, 2, 916; (j) S. Carboni, C. Gennari, L. Pignataro and U. Piarulli, Dalton Trans., 2011, 40, 4355; (k) P. J. Deuss, R. den Heeten, W. Laan and P. C. J. Kamer, Chem. - Eur. J., 2011, 17, 4680; (I) M. T. Reetz, Chem. Rec., 2012, 12, 391; (m) M. Raynal, P. Ballester, A. Vidal-Ferran and P. W. N. M. van Leeuwen, Chem. Soc. Rev., 2014, 43, 1660; (n) M. Raynal, P. Ballester, A. Vidal-Ferran and P. W. N. M. van Leeuwen, Chem. Soc. Rev., 2014, 43, 1734.

7 See, for example references $6 j, m, n$ and: (a) R. H. Crabtree, New J. Chem., 2011, 35, 18; (b) E. Lindbäck, S. Dawaigher and K. Wärnmark, Chem. - Eur. J., 2014, 20, 13432; (c) P. Dydio and J. N. H. Reek, Chem. Sci., 2014, 5, 2135.

8 See, for example: (a) T. S. Koblenz, J. Wassenaar and J. N. H. Reek, Chem. Soc. Rev., 2008, 37, 247; (b) M. Yoshizawa, J. K. Klosterman and M. Fujita, Angew. Chem., Int. Ed. 2009, 48, 3418; (c) S. H. A. M. Leenders, R. GramageDoria, B. de Bruin and J. N. H. Reek, Chem. Soc. Rev. 2015, 44, 433.

9 The underlying principle is to design enantiopure ligands that incorporate several independent modules or molecular fragments. Such modules are designed to influence the catalytic site, whereby their sterics and electronics are considered input parameters for catalyst optimisation. Selective modification of these parameters-based on mechanistic insight, molecular recognition principles, or even the intuition of chemists themselves-has generally yielded higher-performing catalytic systems in terms of conversion, enantioselectivity and substrate scope. For some early examples of this methodology, see for example: (a) B. M. Trost, D. L. Van Vranken and C. Bingel, J. Am. Chem. Soc., 1992, 114, 9327; (b) T. V. Rajanbabu, A. L. Casalnuovo and T. A. Ayers, Adv. Catal. Processes, 1997, 2, 1; (c) A. VidalFerran, A. Moyano, M. A. Pericàs and A. Riera, J. Org. Chem., 1997, 62, 4970.

10 See, for example reference $6 \mathrm{~d}$ and: (a) H. Wennemers, Comb. Chem. High Throughput Screening, 2001, 4, 273; (b) A. H. Hoveyda and K. E. Murphy in Comprehensive Asymmetric Catalysis: Supplement I, eds. E. N. Jacobsen, A. Pfaltz and H. Yamamoto, Springer-Verlag, Heidelberg, 1st edn., 2004; vol. 1, pp 171; (c) C. Jäkel and R. Paciello, Chem. Rev., 2006, 106, 2912; (d) C. A. Busacca, D. R. Fandrick, J. J. Song and C. H. Senanayake, Adv. Synth. Catal., 2011, 353, 1825; (e) D. Leung, S. O. Kang and E. V. Anslyn, Chem. Soc. Rev., 2012, 41, 448.

11 See, for example: (a) J. F. Traverse and M. L. Snapper, Drug Discovery Today, 2002, 7, 1002; (b) C. Markert, P. Roesel and A. Pfaltz, J. Am. Chem. Soc., 2008, 130, 3234.

12 See, for example: (a) M. F. Perutz, G. Fermi, B. Luisi, B. Shaanan and R. C. Liddington, Acc. Chem. Res., 1987, 20, 309; (b) R. Grandori, T. A. Lavoie, M. Pflumm, G. Tian, H. Niersbach, W. K. Maas, R. Fairman and J. Carey, J. Mol. Biol., 1995, 254, 150.

13 Progress has been made by using a regulation agent in regulating the size and shape of an enantioselective catalyst, in changing the first-sphere coordination geometry of the active metal in enantioselective catalysis, or even in switching on and off the activity of the enantioselective catalyst. For general reviews which contain examples of major regulation effects in catalysis of achiral and enantioselective transformations, see: (a) L. Kovbasyuk and R. Kraemer, Chem. Rev., 2004, 104, 3161; (b) N. C. Gianneschi, M. S. Masar, III and C. A. Mirkin, Acc. Chem. Res., 2005, 38, 825; (c) Y. Kubo and Y. Ishii, J. Nanosci. Nanotechnol., 2006, 6, 1489; (d) L. Zhu and E. V. Anslyn, Angew. Chem., Int. Ed., 2006, 45, 1190; (e) S. J. Lee and W. Lin, Acc. Chem. Res., 2008, 41, 521; (f) M. J. Wiester, P. A. Ulmann and C. A. Mirkin, Angew. Chem., Int. Ed., 2011, 50, 114; (g) C. Kremer and A. Luetzen, Chem. Eur. J., 2013, 19, 6162; (h) N. Kumagai and M. Shibasaki, Catal. Sci. Technol., 2013, 3, 41; (i) V. Blanco, D. A. Leigh and V. Marcos, Chem. Soc. Rev., 2015, 44, 5341.

14 For example, see: (a) D. J. Cram, Angew. Chem. Int. Ed. Engl., 1988, 100, 1009; (b) C. J. Pedersen, Angew. Chem. Int. Ed. Engl., 1988, 100, 1021; (c) A. V. Bajaj and N. S. Poonia, Coord. Chem. Rev., 1988, 87, 55; (d) F. C. J. M. van Veggel, W. Verboom and D. N. Reinhoudt, Chem. Rev., 1994, 94, 279

15 M. Sawamura, Y. Nakayama, W.-M. Tang and Y. Ito, J. Org. Chem., 1996, 61, 9090.

16 M. Sawamura and Y. Ito, Chem. Rev., 1992, 92, 857.

17 H. Fernández-Pérez, I. Mon, A. Frontera and A. VidalFerran, Tetrahedron, 2015, 71, 4490.

18 For selected reviews on the concept of natural bite-angle and its effects, see: (a) P. W. N. M. van Leeuwen, P. C. J. Kamer, J. N. H. Reek and P. Dierkes, Chem. Rev., 2000, 100, 2741; (b) H. Shimizu, I. Nagasaki and T. Saito, Tetrahedron, 2005, 61, 5405, and the references cited therein. 
19 X.-C. Zhang, Y.-H. Hu, C.-F. Chen, Q. Fang, L.-Y. Yang, Y.-B. Lu, L.-J. Xie, J. Wu, S. Li and W. Fang, Chem. Sci., 2016, 7, 4594.

20 For application of Xyl-P-Phos ligand in Rh-mediated AHs, see: (a) J. Wu, C. C. Pai, W. H. Kwok, R. W. Guo, T. T. L. AuYeung, C. H. Yeung and A. S. C. Chan, Tetrahedron: Asymmetry, 2003, 14, 987. For application of Xyl-P-Phos ligand in Ir-mediated AH, see: (b) L. Xu, K. H. Lam, J. Ji, J. $\mathrm{Wu}$, Q.-H. Fan, W.-H. Lo and A. S. C. Chan, Chem. Commun., 2005, 1390.

21 Ligand Xyl-P-Phos = 2,2',6,6'-tetramethoxy-4,4'-bis[di(3,5dimethylphenyl)phosphino]-3,3'-3,3-phosphino]-3,3-

tetramethoxy-4,4'-bis-[di(3,5-dimethyl-

phenyl)phosphino], developed by A. S. C. Chan et al.: J. Wu, H. Chen, W.-H. Kwok, C.-H. K.-H. Lam, Z.-Y. Zhou, C.H. Yeung and A. S. C. Chan, Tetrahedron Lett., 2002, 43, 1539.

22 Y. Li, B. Ma, Y. He, F. Zhang and Q.-H. Fan, Chem. Asian J., 2010, 5, 2454.

23 For seminal examples of applications of metallacrownethers in catalysis, see: (a) S. B. Owens, Jr. and G. M. Gray, Organometallics, 2008, 27, 4282; (b) X. Zhang, Y. Qiu, B. Rao and M. Luo, Organometallics, 2009, 28, 3093. Effects of the metallacrown-ether binders on the enantioselectivity of the reaction are not mentioned in ref. 23a. The transformation detailed in ref. 23b is achiral.

24 For selected reviews, see ref. $14 \mathrm{~d}$ and the following references: (a) G. M. Gray, Comments Inorg. Chem., 1995, 17, 95; (b) G. Mezei, C. M. Zaleski and V. L. Pecoraro, Chem. Rev., 2007, 107, 4933.

25 F.-T. Song, G.-H. Ouyang, Y. Li, Y.-M. He and Q.-H. Fan, Eur. J. Org. Chem., 2014, 6713.

26 I. Mon, D. A. Jose and A. Vidal-Ferran, Chem. - Eur. J., 2013, 19, 2720.

27 A. Vidal-Ferran, I. Mon, A. Bauzá, A. Frontera and L. Rovira, Chem. - Eur. J., 2015, 21, 11417.

28 The reader is referred to the original publication for further details.

29 The bite angle of metal complexes has proven to be quite important for the regioselectivity in hydroformylation reactions of internal and terminal olefins, as it might dictate the ligand coordination mode between various possible coordination isomers. For selected reviews on this topic, see reference $18 \mathrm{a}$ and: P. W. N. M. van Leeuwen, P. C. J. Kamer, L. A. van der Veen and J. N. H. Reek, Chin. J. Chem., 2001, 19, 1.

30 (a) Unpublished results; (b) L. Rovira, M. Vaquero and A. Vidal-Ferran, J. Org. Chem., 2015, 80, 10397.

31 G.-H. Ouyang, Y.-M. He and Q.-H. Fan, Chem. - Eur. J., 2014, 20, 16454.

32 L. Rovira, H. Fernández-Pérez and A. Vidal-Ferran, Organometallics, 2016, 35, 528.

33 J. A. Fuentes, T. Lebl, A. M. Z. Slawin and M. L. Clarke, Chem. Sci., 2011, 2, 1997.

34 P. Dydio, C. Rubay, T. Gadzikwa, M. Lutz and J. N. H. Reek, J. Am. Chem. Soc., 2011, 133, 17176.

35 L. Théveau, R. Bellini, P. Dydio, Z. Szabo, A. van der Werf, S. Afshin, J. N. H. Reek and C. Moberg, Organometallics, 2016, 35, 1956. 